OPEN ACCESS

Edited by:

Wendy Schluchter,

University of New Orleans, USA

Reviewed by:

Qingfang $\mathrm{He}$

University of Arkansas at Little Rock,

USA

Jason Warren Cooley,

University of Missouri, USA

*Correspondence:

Beronda L. Montgomery

montg133@msu.edu

Specialty section:

This article was submitted to Microbial Physiology and Metabolism,

a section of the journal

Frontiers in Microbiology

Received: 23 September 2015 Accepted: 23 November 2015

Published: 14 December 2015

Citation:

Busch AWU and Montgomery BL (2015) The Tryptophan-Rich Sensory

Protein (TSPO) is Involved

in Stress-Related

and Light-Dependent Processes

in the Cyanobacterium Fremyella

diplosiphon. Front. Microbiol. 6:1393.

doi: 10.3389/fmicb.2015.01393

\section{The Tryptophan-Rich Sensory Protein (TSPO) is Involved in Stress-Related and Light-Dependent Processes in the Cyanobacterium Fremyella diplosiphon}

\author{
Andrea W. U. Busch ${ }^{1}$ and Beronda L. Montgomery ${ }^{1,2 *}$ \\ ' Department of Energy - Plant Research Laboratory, Michigan State University, East Lansing, MI, USA, ${ }^{2}$ Department of \\ Biochemistry and Molecular Biology, Michigan State University, East Lansing, MI, USA
}

The tryptophan-rich sensory protein (TSPO) is a membrane protein, which is a member of the $18 \mathrm{kDa}$ translocator protein/peripheral-type benzodiazepine receptor (MBR) family of proteins that is present in most organisms and is also referred to as Translocator protein $18 \mathrm{kDa}$. Although TSPO is associated with stress- and diseaserelated processes in organisms from bacteria to mammals, full elucidation of the functional role of the TSPO protein is lacking for most organisms in which it is found. In this study, we describe the regulation and function of a TSPO homolog in the cyanobacterium Fremyella diplosiphon, designated FoTSPO. Accumulation of the FdTSPO transcript is upregulated by green light and in response to nutrient deficiency and stress. A F. diplosiphon TSPO deletion mutant (i.e., $\triangle F d T S P O$ ) showed altered responses compared to the wild type (WT) strain under stress conditions, including salt treatment, osmotic stress, and induced oxidative stress. Under salt stress, the FdTSPO transcript is upregulated and a $\triangle F d T S P O$ mutant accumulates lower levels of reactive oxygen species (ROS) and displays increased growth compared to WT. In response to osmotic stress, FdTSPO transcript levels are upregulated and $\triangle F d T S P O$ mutant cells exhibit impaired growth compared to the WT. By comparison, methyl viologen-induced oxidative stress results in higher ROS levels in the $\triangle F d T S P O$ mutant compared to the WT strain. Taken together, our results provide support for the involvement of membranelocalized FoTSPO in mediating cellular responses to stress in F. diplosiphon and represent detailed functional analysis of a cyanobacterial TSPO. This study advances our understanding of the functional roles of TSPO homologs in vivo.

Keywords: cyanobacteria, light signaling, osmotic stress, oxidative stress, reactive oxygen species (ROS), salt stress, tryptophan-rich sensory protein (TSPO)

\section{INTRODUCTION}

Cyanobacteria are capable of adapting to various environments as evident by their ubiquitous distribution in fresh and salt water bodies as well as arid areas (Whitton and Potts, 2000). These organisms exhibit developmental plasticity in response to environmental cues such as light and/or nutrients to tune growth and development to their environment. The large peripheral lightharvesting antennae, the phycobilisomes (PBSs), that are found in cyanobacteria transfer absorbed 
light energy to the core photosystems to enable efficient light-harvesting under different light qualities and quantities (Grossman et al., 1993; Watanabe and Ikeuchi, 2013). The filamentous, freshwater cyanobacterium Fremyella diplosiphon is a model organism for complementary chromatic acclimation (CCA; Bennett and Bogorad, 1973; Kehoe and Grossman, 1994; Kehoe and Gutu, 2006). During CCA, the composition of PBSs is varied in this organism through transcriptional control of phycobiliprotein biosynthesis depending on the external light quality (Gutu and Kehoe, 2012). F. diplosiphon synthesizes two major phycobiliproteins that make up the external portion of the PBS rods, the green light- (GL) absorbing phycoerythrin (PE) and the red light- (RL) absorbing phycocyanin (PC; Takemoto and Bogorad, 1975; Conley et al., 1988). The phycobilin chromophores that confer the PBSs with their specific absorption characteristics are open-chain tetrapyrroles covalently attached to the phycobiliproteins (Frankenberg et al., 2001).

Tetrapyrroles are involved in many important processes in cells, including respiration, photosynthesis, and methanogenesis (Warren and Smith, 2009). Tetrapyrrole biosynthesis bifurcates into the heme branch and the chlorophyll branch after the formation of cyclic tetrapyrrole protoporphyrin IX (Warren and Smith, 2009). Heme biosynthesis requires chelation of iron, while its oxidative cleavage to form the open chain-tetrapyrroles, including those used to synthesize PBSs, involves iron release (Ferreira et al., 1995; Unno et al., 2007). Therefore, a tight regulation of tetrapyrrole synthesis and iron homeostasis is indispensable for regulating oxidative stress responses (Busch and Montgomery, 2015), especially due to the photosensitizing activity of tetrapyrroles (Aravind Menon et al., 1989) and the function of iron as a cofactor in fighting oxidative stress (Busch and Montgomery, 2015).

Responses to light, availability of iron and other nutrients, tetrapyrrole metabolism, and oxidative stress are co-regulated. For example, iron uptake and transport are light-regulated in photosynthetic organisms, often linked to photoreceptors (Montgomery et al., 2015). In F. diplosiphon the photoreceptor RcaE controls not only chromatic acclimation (Kehoe and Grossman, 1996; Terauchi et al., 2004), but is also involved in acclimation to iron-deficiency (Pattanaik et al., 2014). Degradation of light-harvesting PBSs as well as a restructuring of the photosynthetic apparatus can reduce oxidative stress under high-light exposure and/or nutrient deficiency (Narayan et al., 2011; Busch and Montgomery, 2015). Also, tetrapyrrole metabolism is largely controlled by light and involves feedback regulation by heme in photosynthetic organisms (Warren and Smith, 2009). Our aim was to identify factors involved in the process of integrating light and stress responses with pigment metabolism.

The tryptophan-rich outer membrane sensory protein (tryptophan-rich sensory protein, TSPO), more recently referred to as translocator protein $18 \mathrm{kDa}$ (TSPO) although its role as a ubiquitous transporter is still under debate (Batoko et al., 2015), is an outer membrane protein in photosynthetic and non-photosynthetic organisms that appears to be involved in tetrapyrrole metabolism, stress adaptation and regulation of carotenoid biosynthesis (Yeliseev and Kaplan, 1995, 1999; Davey and de Bruijn, 2000; Papadopoulos et al., 2006; Guillaumot et al., 2009; Balsemão-Pires et al., 2011; Vanhee et al., 2011). TSPO was first identified and studied in mammals where it was previously called peripheral-type benzodiazepine receptor (Braestrup et al., 1977). Although present in various genomes throughout all kingdoms of life, including vertebrates, invertebrates, plants, some yeasts (i.e., found in Schizosaccharomyces pombe, but not in Saccharomyces cerevisiae) and bacteria, TSPO is not ubiquitous. It belongs to a family of membrane proteins (Pfam: TspO/MBR family PF03073) that bind a large variety of ligands and functions for TSPO in stress, photosynthesis, membrane transport, and human diseases all have been implicated (Yeliseev and Kaplan, 1999; Wendler et al., 2003; Balsemão-Pires et al., 2011; Colasanti et al., 2013; Wu and Gallo, 2013).

A TSPO homolog is expressed in F. diplosiphon (Luque et al., 2003; Stowe-Evans et al., 2004). FdTSPO expression was reported as increased in nitrogen-replete medium (Luque et al., 2003) or by GL (Stowe-Evans et al., 2004). To investigate the functional role of TSPO in responses to light and stress in F. diplosiphon, we produced a complete deletion of the TSPO homolog $(\triangle F d T S P O)$ in this organism. Comparative phenotypical analyses of $\triangle F d T S P O$ and wild type (WT) cells grown under salt stress demonstrated that the $\triangle F d T S P O$ mutant exhibited lower pigment content and decreased ROS levels, whereas growth was increased in the $\triangle F d T S P O$ mutant compared to WT under these conditions. Under osmotic stress conditions, the $\triangle F d T S P O$ mutant grew slower than WT. The salt and osmotic stressdependent observations were light-quality dependent. Induction of oxidative stress by methyl viologen (MV) resulted in higher ROS levels in the mutant compared to the WT under GL. The $\triangle F d T S P O$ mutant also exhibited altered light-dependent regulation of cellular morphology compared to WT. Our results provide evidence that FdTSPO functions during organismal responses to stress and exhibits distinct light-quality dependent roles in F. diplosiphon.

\section{MATERIALS AND METHODS}

\section{Bacterial Strains and Growth Conditions}

Fremyella diplosiphon strain SF33, which is a short filament, wild-type pigmentation strain (Cobley et al., 1993), was used as the WT parent. F. diplosiphon strains were grown at $28^{\circ} \mathrm{C}$ in BG-11 medium (Fluka, Buchs, Switzerland) with $20 \mathrm{mM}$ HEPES (hereafter BG-11/HEPES) with shaking at $175 \mathrm{rpm}$ at $\sim 10 \mu \mathrm{mol} \mathrm{m} \mathrm{m}^{-2} \mathrm{~s}^{-1}$ of continuous broad-band GL (CVG sleeved Rosco green 89 fluorescent tubes, General Electric; model no. F20T12/G78) or continuous broad-band RL (CVG sleeved Rosco red 24 fluorescent tubes, General Electric; model no. F20T12/R24). Light intensities were measured using an LI-250A light meter (LI-COR, Lincoln, NE) equipped with a quantum sensor (LI-COR). Cell densities were determined by measuring the optical density at $750 \mathrm{~nm}\left(\mathrm{OD}_{750}\right)$ using a SpectraMax M2 microplate reader (Molecular Devices, Sunnyvale, CA, USA). Iron-replete and -depleted cells were grown as described previously (Pattanaik et al., 2014). Salt-treated cells were grown in BG-11/HEPES medium supplemented with $200 \mathrm{mM} \mathrm{NaCl}$ at 
$\sim 10 \mu \mathrm{mol} \mathrm{m} \mathrm{m}^{-2} \mathrm{~s}^{-1}$. Osmotic stress treatment was accomplished by growing cells in BG-11/HEPES medium supplemented with $400 \mathrm{mM}$ sorbitol at $\sim 10 \mu \mathrm{mol} \mathrm{m}^{-2} \mathrm{~s}^{-1}$.

Escherichia coli cultures were grown at $37^{\circ} \mathrm{C}$ in Luria-Bertani (LB) broth with the indicated antibiotic [i.e., $100 \mu \mathrm{g} / \mathrm{ml}(\mathrm{w} / \mathrm{v})$ ampicillin, $50 \mu \mathrm{g} / \mathrm{ml} \mathrm{(w/v)} \mathrm{kanamycin,} \mathrm{or} 10 \mu \mathrm{g} / \mathrm{ml} \mathrm{(w/v)}$ neomycin]. For growth on solid medium 1.5\% (w/v) Bacto-Agar in LB was used.

\section{Mutant Generation}

A FdTSPO knock out mutant (i.e., $\triangle F d T S P O$ ) was generated in the WT background. Allelic-exchange vector pJCF276 (Cobley et al., 2002) carrying $\sim 4 \mathrm{~kb}$ of the genomic region containing FdTSPO (GenBank accession number of corresponding protein: AAT36314.1) was constructed. The initial fragment was obtained by amplifying the FdTSPOcontaining genomic region (NcoI restriction sites underlined; forward primer: cctccatgggcgtttagttatctggaaacc, reverse primer: gaaccatggccatcttacgcaatttgg) with Prime Star GXL polymerase (Clontech, Mountain View, CA, USA). The vector and insert were restricted with $\mathrm{NcoI}$ restriction enzyme and ligated with the TaKaRa DNA ligation kit version 2.1 (Clontech, Mountain View, CA, USA). The FdTSPO gene (i.e., 756 bp coding region) was then deleted from this construct by whole-plasmid PCR using the same polymerase and $5^{\prime}$ phosphorylated primers (forward primer: aattaagatattgagcttcgctggtaattattaataataaatcatcagc, reverse primer: atactcaaaattaatttgacatcaatagcagtagagaaattagcaatc) followed by ligation with the TaKaRa DNA ligation kit. The verified donor plasmid was transformed into DH5 $\alpha$ MCR E. coli cells containing the plasmid pJCF173, which contains methylase genes to produce methylated plasmids that are protected from digestion in the F. diplosiphon host (Cobley et al., 1999). Fully segregated transconjugants were obtained essentially using the method described before (Elhai and Wolk, 1988; Cobley et al., 1993, 2002; Pattanaik and Montgomery, 2010). The first selection was carried out on neomycin-containing plates and the second selection was on 5\% sucrose-containing medium. Full segregation was confirmed by comparative PCR using WT and putative mutant $F$. diplosiphon cells as templates. PCR was performed with primers located in the flanking region of FdTSPO (forward primer: caggtgggactggtcac, reverse primer: ttaacaaaagttacgctgc), resulting in a product of 2208 and $1452 \mathrm{bp}$ for the amplified region in WT or $\triangle F d T S P O$, respectively.

\section{Production of Complemented $\Delta F d T S P O$ Strain}

The gene for FdTSPO including its 360 bp upstream region was amplified with primers adding attB-sites for subsequent Gateway ${ }^{\circledR}$ cloning (fwd primer: ggggacaagtttgtacaa aaaagcaggcttcggattgcaggtaagtagagc, reverse primer: ggggaccacttt gtacaagaaagctgggtcttattttccactggtgtgag). The resulting product was cloned into the $\mathrm{pDONR}^{\mathrm{TM}} / \mathrm{Zeo}$ vector according to the manufacturer's instructions. The resulting donor vector was then used in an LR recombination reaction with the pPL2.7GWC vector containing a Gateway ${ }^{\circledR}$ cassette (Bordowitz and Montgomery, 2008). An empty pPL2.7 vector (Cobley et al., 1993) and pPL2.7 containing FdTSPO with its native promoter (pPL2.7_npTSPO) were transformed into WT (SF33) F. diplosiphon cells by means of triparental mating essentially as described (Pattanaik and Montgomery, 2010). Selection was carried out on BG11/HEPES plates containing $25 \mu \mathrm{g} / \mathrm{ml}$ kanamycin.

\section{Growth Measurements}

Cells adapted to the indicated light color at $\sim 10 \mu \mathrm{mol} \mathrm{m} \mathrm{m}^{-2} \mathrm{~s}^{-1}$ were diluted in exponential phase to an $\mathrm{OD}_{750}$ of 0.1 to initiate growth experiments. Cell density was measured as $\mathrm{OD}_{750}$ in twoor 3-day intervals. The growth was measured for at least three biological replicates. Growth curves were obtained for WT and $\triangle$ FdTSPO cells under controlled-environment conditions in GL or $\mathrm{RL}$ at fluence rates of $\sim 10 \mu \mathrm{mol} \mathrm{m} \mathrm{m}^{-2} \mathrm{~s}^{-1}$.

\section{ROS Measurements}

Reactive oxygen species measurements were performed using a cell-permeable ROS-sensitive $2^{\prime}, 7^{\prime}$-dichlorodihydrofluorescein diacetate (DCFH-DA) dye essentially as described before (Singh and Montgomery, 2012) with the following adjustments. Before every DCFH-DA addition, cells with an $\mathrm{OD}_{750}>0.2$ were diluted with growth medium to $\mathrm{OD}_{750}=0.2 \mathrm{in} 1 \mathrm{ml}$ of medium.

Methyl viologen dichloride (Sigma-Aldrich, St.Louis, MO, USA) was added from a $1 \mathrm{mM}(\mathrm{w} / \mathrm{v})$ stock solution in $\mathrm{ddH}_{2} \mathrm{O}$ to a final concentration of $0.3 \mu \mathrm{M}(\mathrm{v} / \mathrm{v})$ in the liquid medium. Salt-treated cells were treated as described above. ROS content was measured before and $72 \mathrm{~h}$ after treatment with MV and after 6 days of growth in $200 \mathrm{mM}$ salt.

\section{Microscopy-based Analysis of Cellular Morphology}

Slide preparation and confocal laser scanning microscope imaging were conducted to determine cell size essentially as described previously (Bordowitz and Montgomery, 2008, 2010). Cells in the exponential phase were diluted to $\mathrm{OD}_{750}=0.1$ and grown in the respective light for an additional 3 days prior to imaging.

\section{Pigment Extraction and Quantification}

Phycobiliproteins, chlorophyll $a(\operatorname{chl} a)$ and carotenoids were extracted and quantified as described (Tandeau de Marsac and Houmard, 1988; Kahn et al., 1997; Bordowitz and Montgomery, 2008), with minor modifications. A cell pellet equivalent to $1 \mathrm{ml}$ of a culture at $\mathrm{OD}_{750}=0.6$ was harvested in mid- to late exponential phase. Phycobiliprotein extraction was performed for up to $90 \mathrm{~min}$. Calculations were conducted as previously described (Dere et al., 1998; Bordowitz and Montgomery, 2008).

\section{Reverse Transcription Polymerase Chain Reaction}

Wild type or $\triangle F d T S P O$ cells were grown in the respective light condition to exponential phase and diluted to $\mathrm{OD}_{750}=0.6$ in BG11/HEPES before being grown for an additional $16 \mathrm{~h}$. For analysis of sorbitol treatment after dilution and growth for $16 \mathrm{~h}$, a $10 \mathrm{ml}$ sample was taken as the $0 \mathrm{~h}$ time point and 
the remaining culture was pelleted at $4^{\circ} \mathrm{C}$ at $4750 \mathrm{rpm}$ for $10 \mathrm{~min}$. The pellet was resuspended in $40 \mathrm{ml}$ of BG11/HEPES containing $400 \mathrm{mM}$ of sorbitol to initiate osmotic stress. For analysis of salt or MV treatment, after removing a $10 \mathrm{ml}$ sample for the $0 \mathrm{~h}$ pre-treatment timepoint, $\mathrm{NaCl}$ was added to a final concentration of $200 \mathrm{mM}(\mathrm{v} / \mathrm{v})$ or $\mathrm{MV}$ was added to a final concentration of $0.3 \mu \mathrm{M}(\mathrm{v} / \mathrm{v})$. For all samples, i.e., untreated or treated, 10 or $50 \mathrm{ml}$ of culture were harvested and RNA was extracted from the pellet with $1 \mathrm{ml}$ Trizol per sample as described previously (Seib and Kehoe, 2002). Further RNA treatment and reverse transcription (RT) were performed as described before (Singh and Montgomery, 2013a). Primers used for reference gene $O R F 10 B$ were those previously reported (Singh and Montgomery, 2013a). The following primers were used to detect FdTSPO: gtagaacggagattaggtgcg, forward primer; cagccacagttagccagatac, reverse primer. For analysis of FdTSPO abundance in the WT vs. mutant or for sorbitol or MV-treated cells, $500 \mathrm{ng}$ of total RNA were used in a $20 \mu \mathrm{l}$ R reaction containing $1 \mathrm{X}$ buffer, $1.25 \mathrm{mM} \mathrm{MgCl}_{2}$, $1 \mathrm{mM}$ dNTP mix, $0.5 \mu \mathrm{l}$ RNasin, $1 \mu \mathrm{l}$ random primers, and $0.7 \mu \mathrm{l}$ AMVRT. A $10 \mu \mathrm{l}$ qPCR reaction contained $5 \mu \mathrm{l}$ Fast SYBR Green Master Mix, $0.4 \mu \mathrm{M}$ primers, and $4 \mu \mathrm{l}$ of a 1:40 dilution of the $\mathrm{RT}$ reaction using the Microamp $^{(B)}$ fast optical 96-well reaction plate and ABI FAST 7500 Real-Time PCR system (Applied Biosystems, Grand Island, NY, USA) in FAST mode according to the manufacturer's instructions. For analysis of salt treatment, $100 \mathrm{ng}$ of total RNA were used in the RT reaction containing $1 \mathrm{X}$ buffer, $1.25 \mathrm{mM} \mathrm{MgCl}_{2}, 0.25 \mathrm{mM}$ dNTP mix, $0.125 \mu l$ RNasin, $0.25 \mu l$ random primers, and $0.175 \mu \mathrm{l}$ AMVRT. A 1:4 dilution of the RT reaction was used as described above. All experiments were performed with at least three biological replicates with three technical replicates each.

For qualitative reverse transcription PCR (RT-PCR) analyses, a dilution of 1:125 of cDNA was used in a PCR using the GoTaq Green Master Mix with $0.2 \mu \mathrm{M}$ of the following primers: cctgcccagttggtttagc, forward primer; gctgccaaattaatacggaag, reverse primer. The initial denaturation step was performed at $95^{\circ} \mathrm{C}$ for $2 \mathrm{~min}$. For a total of 33 cycles, denaturation was performed at $95^{\circ} \mathrm{C}$, followed by annealing at $51^{\circ} \mathrm{C}$, and elongation at $72^{\circ} \mathrm{C}$ for $30 \mathrm{~s}$ each. The final elongation was performed at $72^{\circ} \mathrm{C}$ for $2 \mathrm{~min}$. A control was performed for ribosomal RNA as previously detailed (Pattanaik and Montgomery, 2010).

\section{Statistical Analyses}

All experiments were performed with at least three independent biological replicates and results are presented as the mean $( \pm S D)$, except for analyses of cellular morphology where mean $( \pm S E)$ was calculated. Three technical replicates were analyzed from each of three biological replicates in qPCR experiments. Data were analyzed with a two-tailed, unpaired Student's $t$-test. If more than two sample groups were analyzed, a one-way ANOVA test for independent samples was performed. If a significant $\mathrm{F}$ ratio was obtained in the ANOVA analyses, a Tukey HSD test was performed.

\section{RESULTS}

\section{FdTSPO is Homologous to Known TSPO Proteins and is Co-localized with Photosynthesis-associated Genes}

An alignment of FdTSPO with TSPO homologs from mammals, fungi, plants and bacteria shows the presence of an N-terminal extension in the FdTSPO sequence (Figure 1A). A similar extension functions as a signaling sequence in Arabidopsis, where alternative start codons also have been associated with different subcellular localization (Balsemão-Pires et al., 2011). As the prokaryotic $F$. diplosiphon does not have the different subcellular organelles associated with AtTSPO targeting in Arabidopsis, the function of this extension in FdTSPO is likely distinct. A possible alternative start codon is located at position M70 in FdTSPO. Notably, putative TSPO homologs of more closely related cyanobacteria like Nostoc show a similar size to that of FdTSPO, which is distinct from the predicted length of a TSPO homolog from Synechocystis (Figure 1A).

FdTSPO is located in the F. diplosiphon genome with unknown gene ORF114, nblA1 (Baier et al., 2004), cpeBA genes (Mazel et al., 1986), and cpeYZ genes (Tandeau de Marsac et al., 1988) downstream (Figure 1B). Upstream of FdTSPO is an ORF with sequence homology to a gene encoding pheophorbide $a$ oxygenase, an enzyme that is involved in chlorophyll breakdown (Hörtensteiner et al., 1995). In F. diplosiphon, the cpeBA genes encode subunits of GL-absorbing photosynthetic pigment PE and the cpeYZ operon encodes the respective lyases that attach the phycoerythrobilin chromophore to the PE subunit (Kahn et al., 1997; Biswas et al., 2011). The expression of these genes is up-regulated under GL (Mazel et al., 1986; Kahn et al., 1997), as has been previously reported for FdTSPO (StoweEvans et al., 2004). Two classes of nblA genes are distinguished, $n b l A 1$ and nblA2. NblA1/2 dimers function in the regulated degradation of PBSs upon nitrogen starvation by acting as an adapter that mediates protease digestion of the PBS in cyanobacteria (Collier and Grossman, 1994; Karradt et al., 2008; Baier et al., 2014). The $n b l A 1$ gene is transcriptionally regulated by nitrogen availability in F. diplosiphon (Luque et al., 2003). The clustering of FdTSPO with genes associated with photosynthesis, specifically with biosynthesis and degradation of tetrapyrroles or tetrapyrrole-containing complexes, suggests a physiologically relevant connection of TSPO with these processes.

Based on the genomic context of TSPO in F. diplosiphon, we analyzed the genetic context of other cyanobacterial TSPOlike genes using the Gene Context Tool (Martinez-Guerrero et al., 2008). Although not a direct parallel to the gene context found in $F$. diplosiphon, photosynthesis-related genes are present in the vicinity of TSPO in Synechococcus sp. PCC 7002 [photosystem I subunit and $p s a L$, which is required for PSI trimer formation in cyanobacteria (Chitnis and Chitnis, 1993)] and in Synechocystis sp. PCC 6803 [protochlorophyllide reductase, DPOR, which is involved in light-independent chlorophyll synthesis (Armstrong, 1998), (Figure 1B)]. Annotated entries for TSPO-like cyanobacterial genes are limited and a homolog is not found in all sequenced cyanobacterial genomes and/or 
A

Synsp._PCC_6803
F_diplosiphon
Nostocssp.PCC_7120
A_thaliana
S_tuberosum
S_pombe
R_sphaeroides
H_sapiens
M_musculus
S_meliloti
P_patens

Syn sp. PCC 6803 F_diplosiphon Nostoc_sp.PCC_7120 A thaliana

stuberosum S_pombe R_sphaeroides H-sapiens

Mrusculus

P_patens

Syn_sp._PCC_6803
F_diplosiphon
Nostoc_sp.PCC_7120
A_thaliana
S_tuberosum
S_pombe
R_sphaeroides
H_sapiens
M_musculus
S_meliloti
P_patens

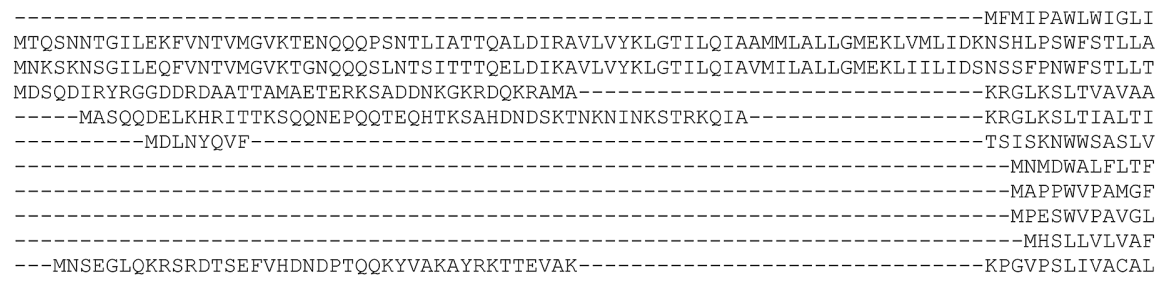

AFA---LAFVCNRLSPRD-LRW---FNRLRR-PSWLTFEWA I PFIWIAIFIAGAISATLAWN-----ATADPGHRWGLMVGYLLLEL VLFFALLSIRSRIFSLLDNTRSRKTYDQVIR-PRWAPP PLVFPIVWMI IAVLRVISSVLIWQ---QMHHQF LALPLILFVVHLALGD ALFFTLLSIRSRI FS LLDNTRSRQTYDQVIR-PKWSPPPLAFP IVWMI IAVLRVISSVLVWQ---OMNHQF LVLPF IMFVVHLALGD PVLVTL--FATYFLGTSDG------YGNRAKSSSWI PPLWLLHTTCLASSGLMGLAAWLVWV-D-GGFHKKPN-ALYLYLAOFLLCL PLLLTL--IDISLFGSSYQ------YVSMEK-PFWFPRLWALHLACLGSSLLMGLSAWLVWA-E-GGFHRKPM-AMLLYLSQLGLSL PVACGW--FIGNSYKPRKD------YENKKQ-PKFHPPASAFGPAWTLLYLTMGYASHLAYKADPLMITNASRNGS ILYIAQLAANF LAACGAPATTGALLKPDE---W---YDNLNK-PWWNP PRWVFPLAWTS LYFLMSLAAMRVAQ------LEGSGQALAFYAAQLAFNT TLAPSLGCFVGSRFVHGEGLRW---YAGLQK-PSWHPPHWVLGPVWGTLYSAMGYGSYLVWK-ELGGFTEKAVVPLGLYTGQLALNW TLVPSLGGFMGAYFVRGEGLRW---YASLOK-PSWHPPRWTLAPIWGTLYSAMGYGSYIVWK-ELGGFTEDAMVPLGLYTGQLALNW EVASFAAAATGVIFRPGD---W---YKOLNK-PRWRPPDWLFALVWAFLYASIGLSGWLVWQ-E-AGIAGAAL-PLGVYAVQLLLNA PLA---AGFLVSMFASPD--QW---YKNLNK-PSWTPPGPLFGLIWTFIYPVMGLASWLVWA-D-GGFQRNGF-ALGAYFVQLGLNL $\cdots$

TVMAYTPVMCKLRSLRVGS-IIGATGFFVGLALVIAVSQVSTTAFGFLVPFLLWSPIGTYVTWAMIPLNPGEI---------T---WNTI FTVERRLGAAVPVVI LGPWLSALVVTAIYWQTNPVAGMIFSESCIWLTVAAVLVFRIWQLNGSEPLYPLKLTPVEK T---WNTI FTVERRLGAAVPVVILGPWLSALVVTA IYWQTNHVAGMI LSF SCIWLTVAAALVFRIWQLNGSEPLYPVKLTPVEE V---WDPVTFRVGSGVAGL-AVWLGQSAALFGCYKAFNE ISPVAGNLVKPCLAWAAFVAAVNVKLAVA-------------

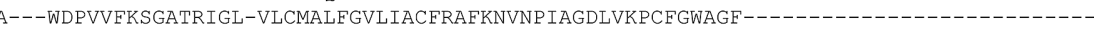
A---WMPLFYGLAKPKLAL-ADLGILTGLVGWLAKTWWPLAPTASKWLI PYLAWLGYAGYLNLGYCLLN------------L---WTPVFFGMKRMATAL-AVVMVMWLFVAATMWAFFQLDTWAGVLFVPYLIWATAATGLNFEAMRLNWNRPEARA------A---WPPIFFGARQMGWAL-VDLLLVSGAAAATTVAWYQVSPLAARLIYPYLAWLAFATTLNYCVWRDNHG---WHGGRRLPEA---WPPIFFGARQMGWAL-ADLLLVSGVATATTLAWHRVSPPAARLIYPYLAWLAFATVLNYYVWRDNSG---RRGGSRLPEA---WTPI FFGLRRPGLAA-VEIMVLWAA I LATTVMFHPVNAAAALILVPYLAWVSFAAALNLS IWRRNRSKTLSQSAR----L---WSVLFFKFHSVTLAF-VDI LALGAAVFTT I GAFQPVNH I AANLMKI Y FGWVVFASVLTASI LMKN-----SRGGH----:

B

Fremyella diplosiphon

phaeophorbide a oxygenase
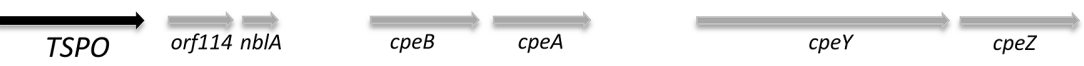

Nostoc sp. PCC 7120

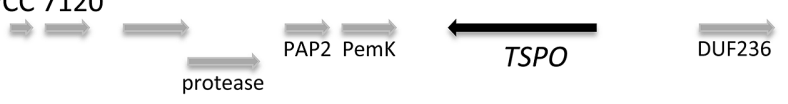

\section{Wzt_C-like}

\section{TSPO phosphatase}

Synechocystis sp. PCC 6803

\section{TSPO}

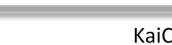

KaiC
DPOR Dpm-synthase

FIGURE 1 | Sequence alignment and representation of genomic context of the putative tryptophan-rich sensor protein (TSPO) in Fremyella diplosiphon compared to other cyanobacterial genomes. (A) Sequence alignment of TSPO homologs from Synechocystis sp. PCC 6803 (Syn_sp._PCC_6803; Accession: BAA18606.1), F. diplosiphon (F_diplosiphon; Accession: AAT36314.1), Nostoc sp. PCC 7120 (Nostoc_sp._PCC_7120; Accession: WP_010997158.1), Arabidopsis thaliana (A_thaliana Accession: NP_566110), Solanum tuberosum (S_tuberosum; Accession: CAH10765.1), Schizosaccharomyces pombe (S_pombe; Accession: NP_595490.2), Rhodobacter sphaeroides 2.4.1 (R_sphaeroides; Accession: WP_002720433.1), Homo sapiens (H_sapiens; Accession: AAA03652.1), Mus musculus (M_musculus; Accession: NP_033905.3), Sinorhizobium meliloti (S_meliloti; Accession: WP_012881280.1), and Physcomitrella patens (P_patens; Accession: ABG37902.1) was generated with CLUSTALW by MUSCLE (3.8) at http://www.ebi.ac.uk/Tools/msa/muscle/ (Edgar, 2004). Symbols below alignment: asterisk indicates positions which have a single, fully conserved residue; colon indicates conservation between groups of strongly similar properties - scoring > 0.5 in the Gonnet PAM 250 matrix; period indicates conservation between groups of weakly similar properties - scoring $\leq 0.5$ in the Gonnet PAM 250 matrix. (B) Arrows represent open reading frames with a black arrow for TSPO. Annotated or known genes have names below the arrows, whereas hypothetical or unknown genes are not labeled.

identification is limited by lack of annotation of TSPO-homologs in known genomes. Therefore, the possibility that the same or a similar genetic context as that observed for $F$. diplosiphon is present in other cyanobacterial genomes cannot be fully excluded. The current analysis highlights the diversity of TSPOflanking sequences in different cyanobacterial species.

\section{FdTSPO is Up-regulated under Green Light}

As noted above, the upregulation of FdTSPO expression under GL conditions has been previously reported for microarray-based analyses (Stowe-Evans et al., 2004). We assessed levels of FdTSPO mRNA based on RNAseq analysis of $F$. diplosiphon cells grown 
under GL and RL (Pattanaik et al., 2014). FdTSPO levels were $\sim 2.5$-fold higher under GL compared to RL in WT (Table 1). The higher accumulation in WT in GL compared to RL was confirmed by quantitative real-time, reverse transcription PCR (qRT-PCR; Figure 2A). FdTSPO transcript levels were higher in a mutant lacking functional RcaE photoreceptor (i.e., $\Delta r c a E$ strain) that controls the CCA response, but levels were still higher on average in GL compared to RL for this $\triangle r c a E$ strain, i.e., 1.7-fold higher in GL (Table 1). A similar observation was made under iron deficiency for WT, with significantly higher levels of FdTSPO mRNA in GL than RL. However, no light quality-dependent regulation of FdTSPO levels was observed under iron depletion in $\Delta r c a E$ (i.e., $\Delta r c a E /-F e$ ) with overall lower levels of FdTSPO mRNA than for any other condition or strain apart from WT cells under RL (Table 1). Our lab previously reported an involvement of RcaE in regulation of iron acclimation in $F$. diplosiphon (Pattanaik et al., 2014). Additionally, an association of TSPO and iron has been suggested for Pseudomonas (Leneveu-Jenvrin et al., 2014). Our current data show that TSPO expression is regulated by light quality and possibly by iron content, although no significant difference in internal iron availability was observed between WT and $\triangle F d T S P O$ mutant strains (Supplementary Figure S1).

\section{TSPO is Not Essential in F. diplosiphon}

A F. diplosiphon mutant lacking FdTSPO, deleting which was designated $\triangle F d T S P O$, was generated by the locus for FdTSPO via homologous recombination (Cobley et al., 1993; Pattanaik and Montgomery, 2010). Genotyping with primers located just outside the FdTSPO gene did not result in a signal for WT copies (i.e., 2208 bp product) in the mutant (Figure 2B). Furthermore, a lack of FdTSPO transcript accumulation was confirmed by qualitative reverse transcription PCR (Figure 2C) and qRT-PCR (Figure 2A). As the $\triangle F d T S P O$ mutant was able to grow in the absence of WT copies of the gene, FdTSPO does not appear

TABLE 1 | RNA sequencing-based analyses of FdTSPO accumulation in F. diplosiphon SF33 wild type (WT) and RcaE photoreceptor mutant ( $\triangle$ rcaE) under green light (GL) or red light (RL) growth in replete $(+\mathrm{Fe})$ or iron-limited (-Fe) medium.

\begin{tabular}{|c|c|c|c|c|c|c|}
\hline \multirow[t]{3}{*}{ Sample } & \multicolumn{2}{|c|}{ No. of reads/WT } & \multirow{3}{*}{$\frac{\text { Fold change }^{a}}{\text { GL/RL }}$} & \multicolumn{3}{|c|}{$p$-value ${ }^{b}$} \\
\hline & \multirow[t]{2}{*}{ GL } & \multirow[t]{2}{*}{$\mathbf{R L}$} & & \multirow[t]{2}{*}{ GL vs. RL } & \multicolumn{2}{|c|}{ WT vs. sample } \\
\hline & & & & & GL & $\mathbf{R L}$ \\
\hline WT & 16.8 & 6.65 & 2.5 & 0.03 & - & - \\
\hline$\Delta r c a E$ & 25.6 & 14.9 & 1.7 & 0.19 & 0.35 & 0.05 \\
\hline WT/-Fe & 27.9 & 10.8 & 2.6 & 0.03 & 0.14 & 0.17 \\
\hline$\Delta r c a E /-F e$ & 8.7 & 9.0 & 0.97 & 0.88 & 0.37 & 0.44 \\
\hline
\end{tabular}

The ORF representing FdTSPO was determined by comparison to Anabaena variabilis ATCC29413 annotated proteins using BLASTX and a cut-off e-value of 0.0001.

a Fold change: differential expression analysis between two light treatments was carried out for each strain. Data were extracted for RNA-seq data described in Pattanaik et al. (2014).

${ }^{b} P$-value: the significance value was calculated for counts for indicated comparison using unpaired two-tailed Student's t-test.

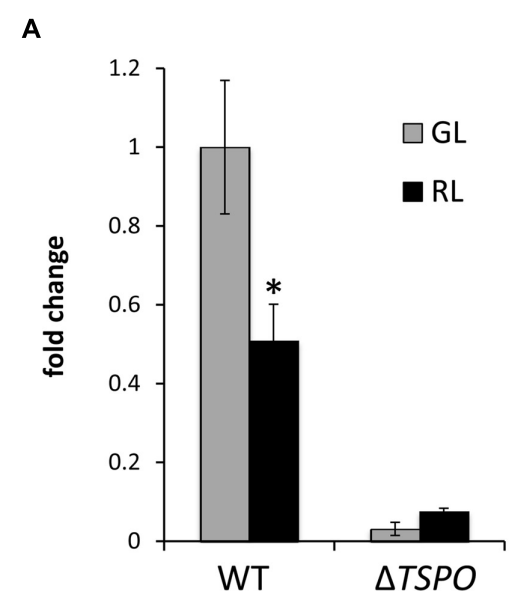

B

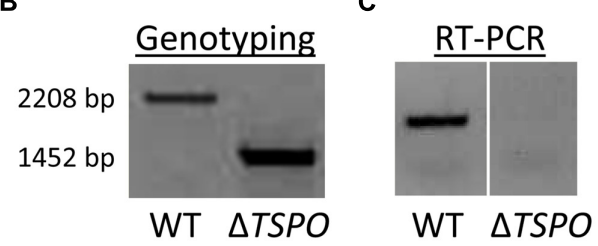

FIGURE 2 | Genotype and reverse transcription analyses of FdTSPO in F. diplosiphon SF33 wild-type and $\triangle F d T S P O$ mutant strains.

(A) Quantitative real-time reverse transcription PCR (qRT-PCR) analysis for wild type (WT) and $\triangle F d T S P O$ mutant strains grown at $10 \mu \mathrm{mol} \mathrm{m}^{-2} \mathrm{~s}^{-1}$ in either green light $(G L)$ or red light $(R L)$. Relative expression level compared to ORF1OB gene is shown ( $\pm \mathrm{SD}, n=3$ ). Fold change of expression of FdTSPO is shown relative to WT cells grown in GL. The asterisk indicates a significant difference $\left({ }^{*} p=0.011\right)$. $P$-values were determined using an unpaired, two-tailed Student's t-test comparing WT in GL vs. RL. (B) PCR analysis of FdTSPO-containing genomic region in WT and $\triangle F d T S P O$ strains.

(C) Qualitative reverse transcription analysis of FdTSPO expression in WT and $\triangle F d T S P O$ background.

essential for the cell, which is consistent with reports from eukaryotic and bacterial TSPO studies (Yeliseev and Kaplan, 1995; Guillaumot et al., 2009; Tu et al., 2014).

\section{$\triangle F d T S P O$ Pigmentation and Growth}

Whole cell absorption spectra of $\triangle F d T S P O$ mutant cells did not differ from the WT under standard light conditions of $\sim 10 \mu \mathrm{mol} \mathrm{m} \mathrm{m}^{-2} \mathrm{~s}^{-1}$ in GL or RL (Supplementary Figure S2). We analyzed the abundance of the phycobiliproteins $\mathrm{PE}, \mathrm{PC}$ and allophycocyanin (AP), and the concentrations of chlorophyll and carotenoids in GL- and RL-grown WT and mutant cells (Figure 3). Levels of chlorophyll and carotenoids were not significantly different in the mutant compared to the WT. Phycobiliprotein content was slightly lower in the mutant compared to the WT only for PE and AP levels under GL, with a maximum difference of a $20.7 \%$ reduction of $\mathrm{PE}$ levels in the mutant under GL compared to the WT (Figure 3). Notably, the defect in $\mathrm{PE}$ and $\mathrm{AP}$ in GL corresponds to the light conditions under which FdTSPO is upregulated in WT. No significant differences in growth of the mutant compared to the WT under 
A

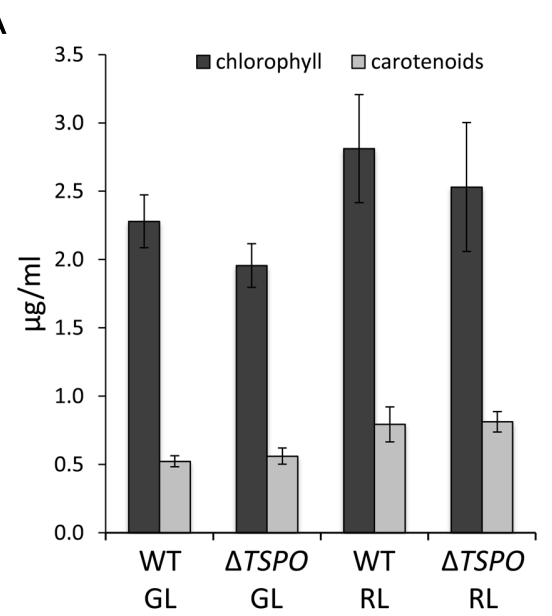

B

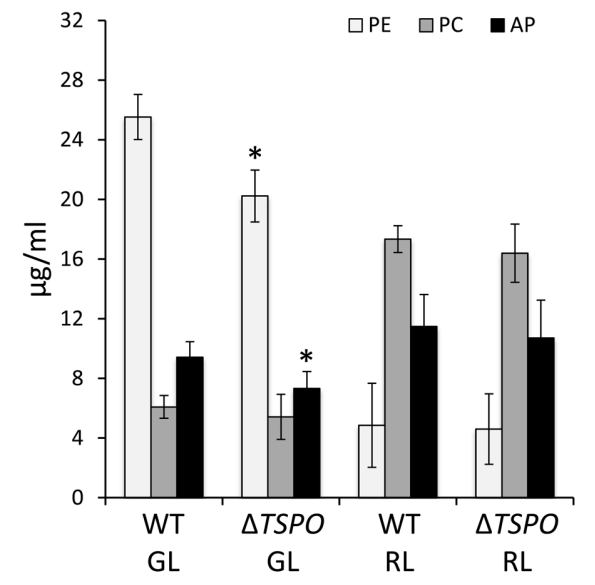

FIGURE 3 | Pigment content of $\boldsymbol{F}$. diplosiphon SF33 wild-type and $\Delta$ FdTSPO mutant strains under standard conditions. WT and FdTSPO mutant ( $\triangle T S P O$ ) cells were grown at $\sim 10 \mu \mathrm{mol} \mathrm{m}^{-2} \mathrm{~s}^{-1}$ under $\mathrm{GL}$ or $\mathrm{RL}$. (A) Chlorophyll and carotenoid contents and (B) phycobiliprotein levels were measured from an equal aliquot of cells as determined by optical density at $750 \mathrm{~nm}\left(\mathrm{OD}_{750}\right)$. Bars represent mean $( \pm \mathrm{SD}, n \geq 6)$. Asterisks indicate a significant difference $\left({ }^{*} p<0.01\right)$ between WT and mutant for the same light condition as determined by ANOVA and Tukey test.

A

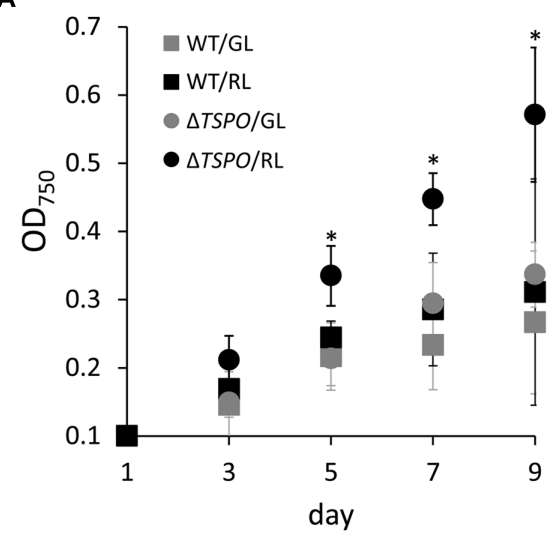

B

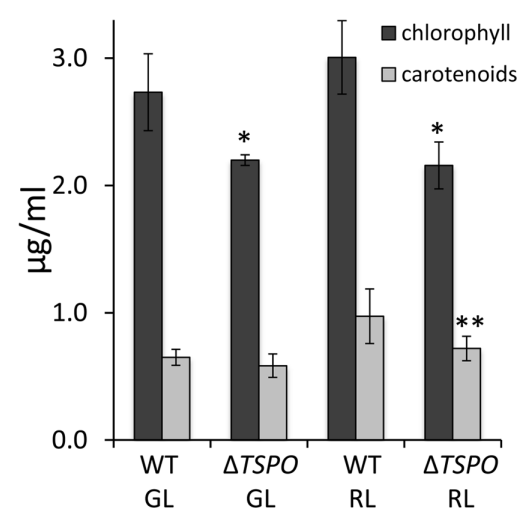

C

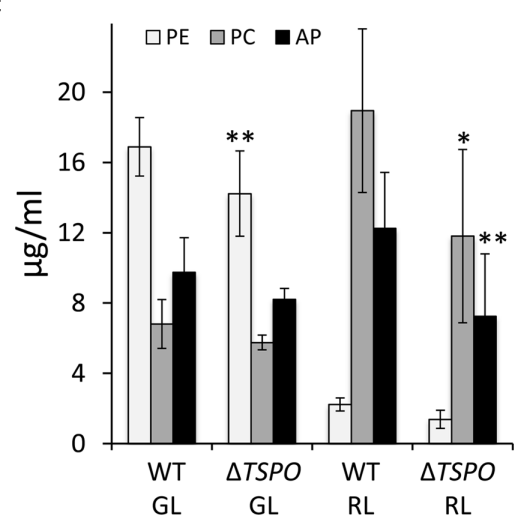

FIGURE 4 | Growth and pigment content in F. diplosiphon SF33 wild-type and $\Delta$ FdTSPO mutant strains under salt stress. (A) WT and FdTSPO mutant $(\triangle T S P O)$ cells were grown at $\sim 10 \mu \mathrm{mol} \mathrm{m} \mathrm{m}^{-2} \mathrm{~s}^{-1}$ in BG-11/HEPES medium containing $200 \mathrm{mM} \mathrm{NaCl}(\mathrm{w} / \mathrm{v})$ and growth was monitored over 8 days at OD 750 . (B) Chlorophyll and carotenoid contents and (C) phycobiliprotein levels were determined after growth in BG-11/HEPES medium containing 200 mM NaCl at $\sim 10 \mu \mathrm{mol} \mathrm{m} \mathrm{m}^{-2} \mathrm{~s}^{-1}$ of $\mathrm{GL}$ or RL. Bars represent mean $( \pm \mathrm{SD}, n \geq 6)$. Asterisks indicate a significant difference $\left({ }^{*} p<0.01, * * p<0.05\right)$ between $\mathrm{WT}$ and mutant for the same light condition $(\mathbf{A}, \mathbf{B})$ or at a given time point $(\mathbf{A})$, as determined by ANOVA and Tukey test. 
A

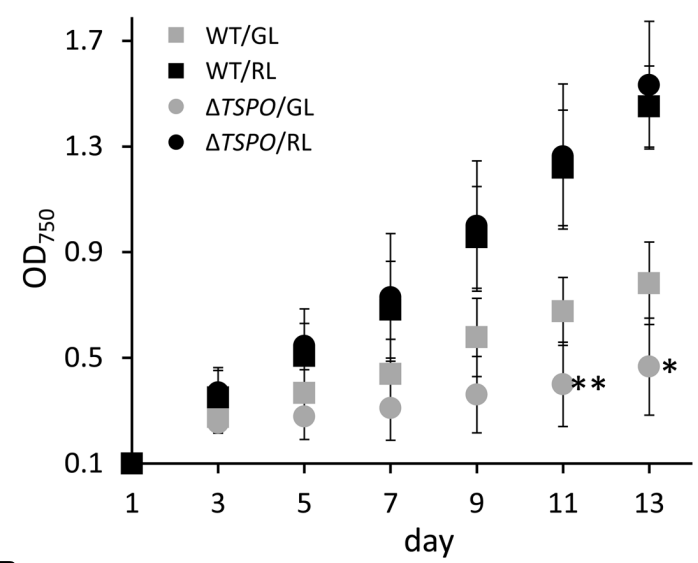

B

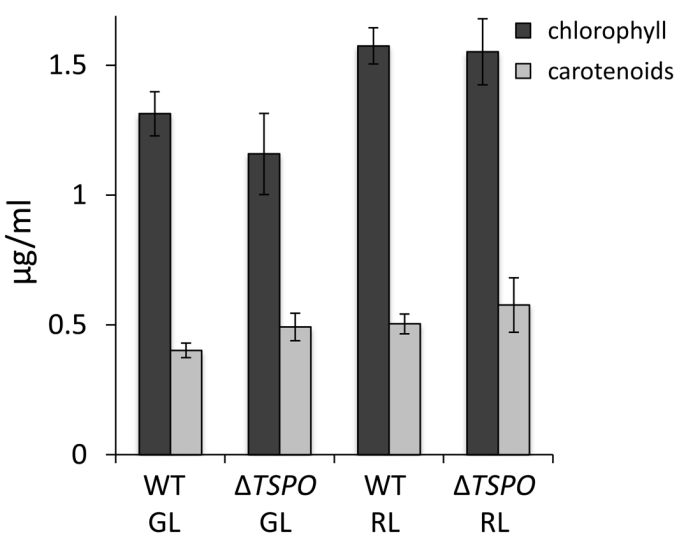

C

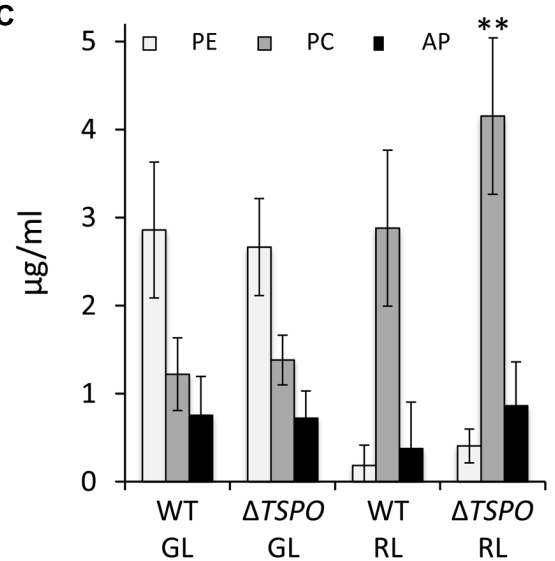

FIGURE 5 | Growth and pigment content in F. diplosiphon SF33 wild-type and $\triangle$ FdTSPO mutant strains under osmotic stress. (A) WT and FdTSPO mutant $(\triangle T S P O)$ cells were grown at $\sim 10 \mu \mathrm{mol} \mathrm{m} \mathrm{m}^{-2} \mathrm{~s}^{-1}$ in BG-11/HEPES medium containing $400 \mathrm{mM}$ sorbitol (w/v) and growth was monitored over 12 days at $\mathrm{OD}_{750}$. (B) Chlorophyll and carotenoid contents and (C) phycobiliprotein levels were determined after growth in BG-11/HEPES medium containing 400 mM sorbitol at $\sim 10 \mu \mathrm{mol} \mathrm{m} \mathrm{m}^{-2} \mathrm{~S}^{-1}$ of $\mathrm{GL}$ or RL. Bars represent mean $( \pm \mathrm{SD}, n=6)$. Asterisks indicate a significant difference $\left.{ }^{*} p<0.01, * * p<0.05\right)$ between $\mathrm{WT}$ and mutant for the same light condition $(\mathbf{A}, \mathbf{B})$ or at a given time point $\mathbf{( A )}$, as determined by ANOVA and Tukey test.

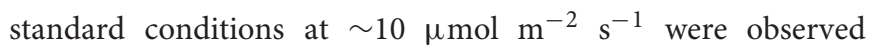
(Supplementary Figure S3).

\section{A Lack of FdTSPO is Correlated with Responses to Stress}

A growth-deficient phenotype due to salt stress was previously reported in WT F. diplosiphon, with the strongest negative impact on growth being observed at $200 \mathrm{mM} \mathrm{NaCl}$ (Singh and Montgomery, 2013b). The $\triangle F d T S P O$ mutant performed significantly better than the WT under salt stress in RL in terms of growth (Figure 4A). Notably, overall photosynthetic pigment levels were lower in the mutant compared to the WT during salt stress (Figures 4B,C). Chlorophyll levels were significantly lower in both light conditions in the mutant, whereas carotenoid levels were significantly lower in the mutant under RL compared to the WT (Figure 4B). Although not significant in the case of $\mathrm{PE}$, a reduction of $\sim 40 \%$ in $\mathrm{PC}, \mathrm{PE}$, and $\mathrm{AP}$ content was observed under RL (Figure 4C), conditions for which differences in growth were greatest (Figure 4A). This salt-induced increase in growth for $\triangle F d T S P O$ relative to WT was specific to TSPO function as it was lost when the $\triangle F d T S P O$ mutant was complemented with a WT TSPO gene driven by its own promoter (Supplementary Figure S4).

Salt stress can induce ionic stress, as well as lower the water potential of cells, thereby resulting in osmotic stress (Hagemann, 2011). We, thus, tested whether part of the alterations in growth observed in response to salt treatment, could also be observed in response to osmotic stress. Osmotic stress induced by sorbitol treatment resulted in distinct responses for the $\triangle$ FdTSPO mutant compared to WT. We observed impairment in growth for the $\triangle F d T S P O$ mutant compared to WT under GL (Figure 5A). Overall the negative effect of sorbitol on growth was much greater in GL than in RL for WT and mutant. Chlorophyll and carotenoid levels were not impacted by sorbitol treatment (Figure 5B). However, significantly higher accumulation of PC was observed for the $\triangle F d T S P O$ mutant under RL in sorbitol-treated cells (Figure 5C). No other significant impacts on the accumulation of phycobiliproteins were noted in either GL or RL in response to sorbitol (Figure 5C). 

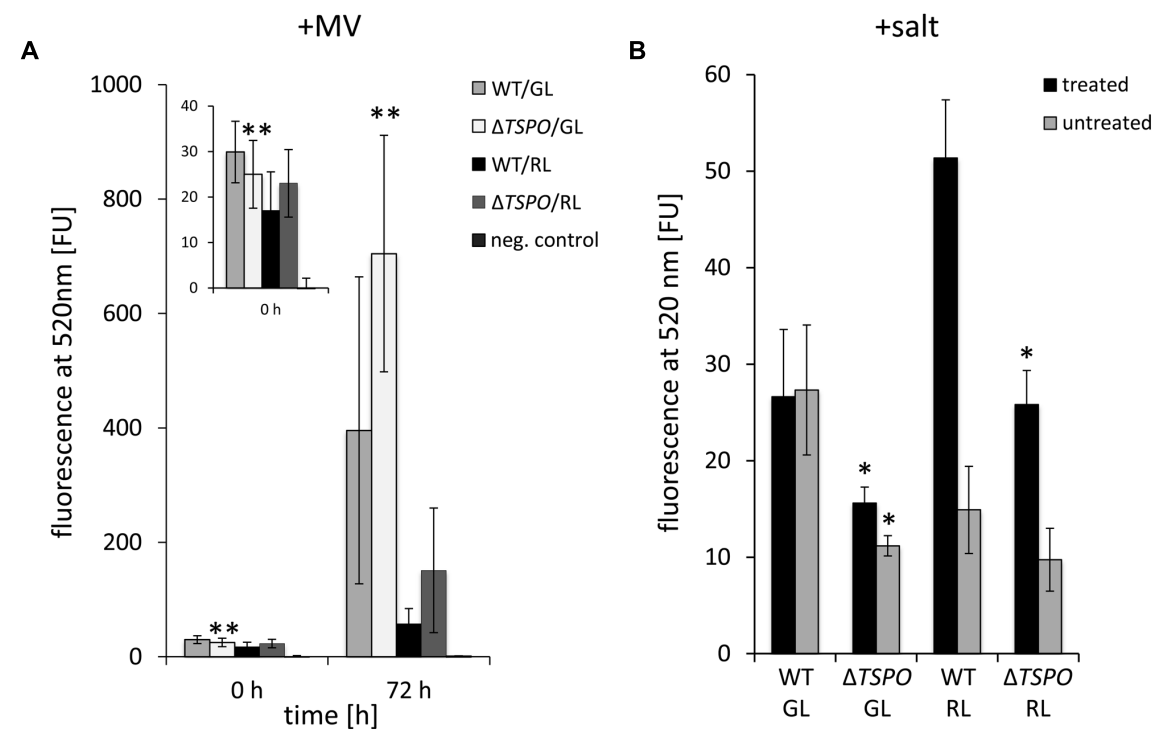

FIGURE 6 | Reactive oxygen species (ROS) content in F. diplosiphon SF33 wild-type and $\Delta$ FdTSPO mutant strains treated with salt and methyl viologen (MV). (A) ROS was measured by DCF-dependent fluorescence at $520 \mathrm{~nm}$ before treatment ( 0 h) and 3 days after addition of $0.3 \mu \mathrm{M} \mathrm{MV} \mathrm{(72} \mathrm{h)} \mathrm{for} \mathrm{WT} \mathrm{and}$ FdTSPO mutant ( $\triangle T S P O)$ cells that were adapted to either GL or RL at $\sim 10 \mu \mathrm{mol} \mathrm{m} \mathrm{m}^{-2} \mathrm{~s}^{-1}$. (B) ROS was measured by DCF-dependent fluorescence at $520 \mathrm{~nm}$ after 6 days of treatment with $200 \mathrm{mM} \mathrm{NaCl}$ (w/v; black bars) or untreated control (gray bars). Bars represent mean ( \pm SD; $n \geq 3$ ). Asterisks indicate a significant difference $\left({ }^{*} p<0.01,{ }^{*} p<0.05\right)$ between WT and mutant for the same light condition at a given time point, as determined by ANOVA and Tukey test.

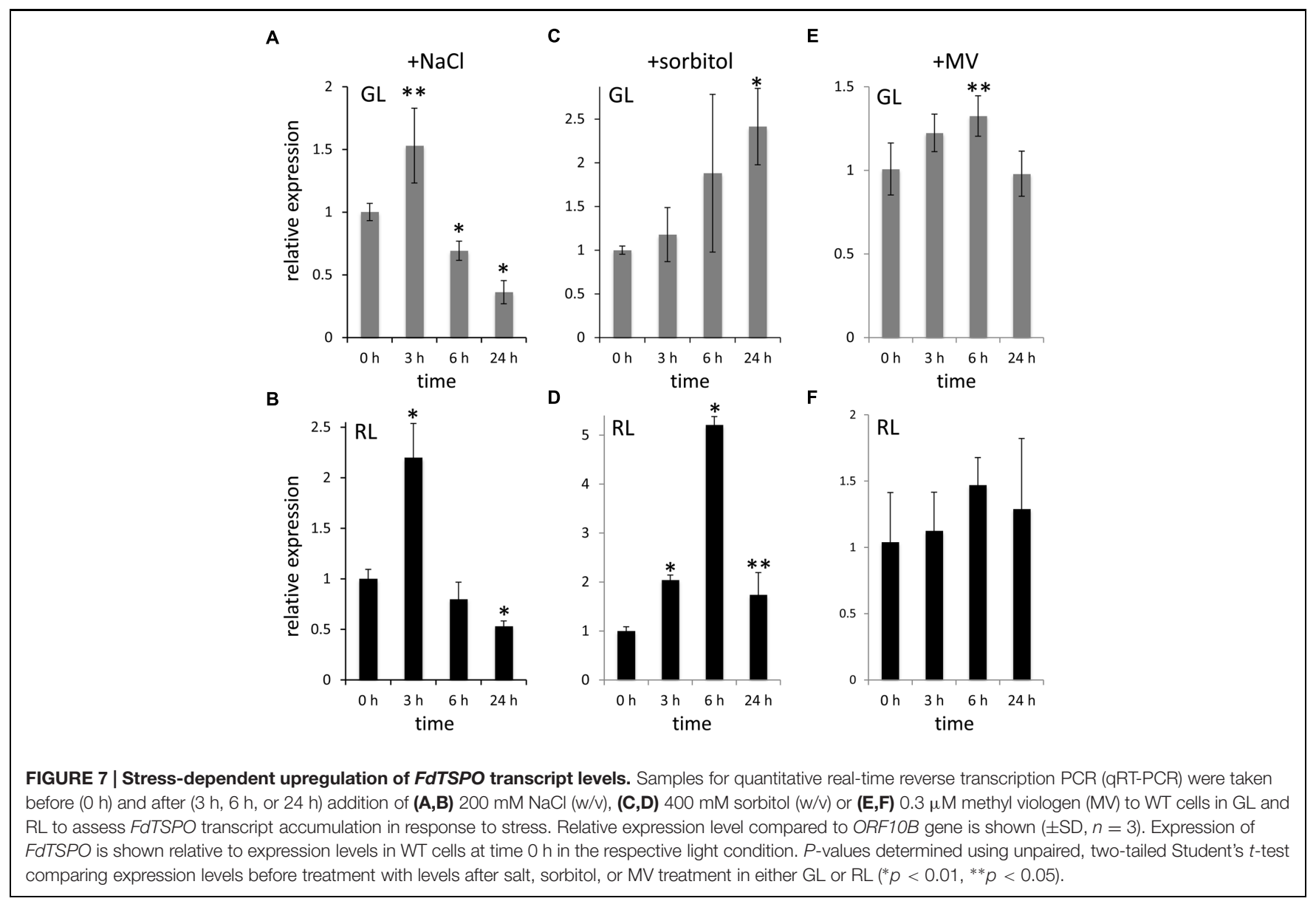


A

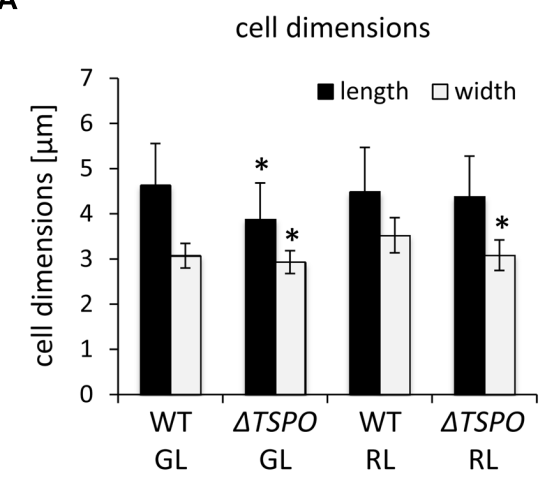

B

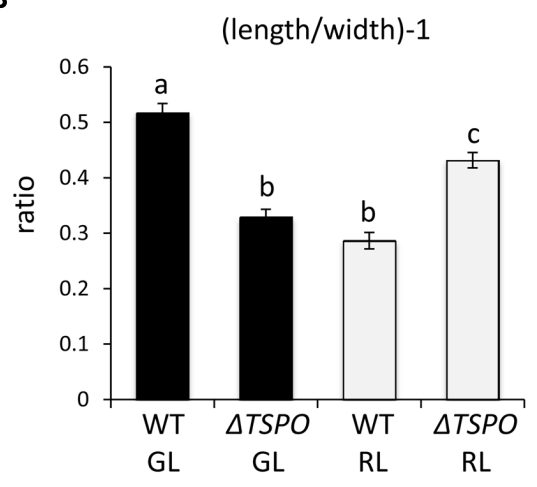

C

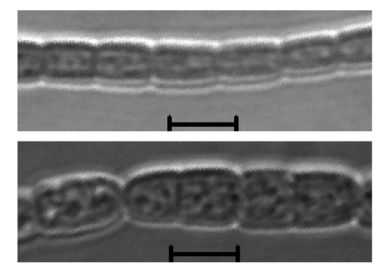

WT

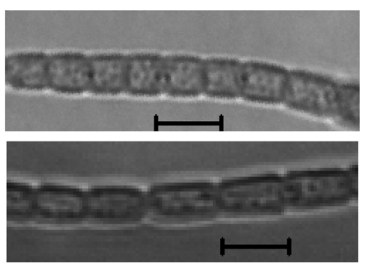

$\triangle T S P O$
GL

$\mathrm{RL}$

FIGURE 8 | Analyses of the cellular morphology of WT and $\triangle F d T S P O$ strains of $\boldsymbol{F}$. diplosiphon grown under GL or RL. (A,B) Cell length and width measurements of WT or mutant ( $\triangle T S P O$ ) cells were obtained for cultures grown in GL or RL at $\sim 10 \mu \mathrm{mol} \mathrm{m} \mathrm{m}^{-2} \mathrm{~s}^{-1}$. These measurements were used to calculate the length-to-width ratio, i.e., $\left(\frac{\text { length }}{\text { width }}\right)$ - 1. Bars represent mean ( \pm SE) for a total of at least 370 individual cells from four independent biological replicates. Asterisks indicate a significant difference $\left({ }^{*} p<0.01\right)$ for the mutant relative to WT for the same light condition and similar letters indicate a homogenous mean group and different letters indicate a significant difference $(* p<0.01)$, as determined by ANOVA and Tukey test. (C) Representative optical slices from a Z-series of differential interference contrast (DIC) images of WT or mutant cells grown under GL or RL for $72 \mathrm{~h}$. Images were acquired using a $40 \times$ oil immersion objective with $2 \times$ zoom setting. Bars, $5 \mu \mathrm{m}$.

\section{$\triangle F d T S P O$ is More Sensitive to Methyl Viologen-induced Oxidative Stress but Shows Less ROS Formation under Salt Stress Compared to WT}

A potential association of FdTSPO with ROS levels was investigated as elevated oxidative stress has been correlated with slower growth and/or cell death in photosynthetic organisms (Busch and Montgomery, 2015). Furthermore, salt stress, which is associated with TSPO function in F. diplosiphon, can cause oxidative stress in cyanobacteria (Srivastava et al., 2008; Srivastava, 2010). TSPO has also been implicated in stress responses in plants (Frank et al., 2007; Guillaumot et al., 2009) and animals (Papadopoulos et al., 2006). AtTSPO overexpression was associated with increased ROS levels and sensitivity to salt in Arabidopsis, which suggested that TSPO enhances oxidative stress signaling in this organism (Vanhee et al., 2011). A PpTSPO1 deletion mutant in the moss Physcomitrella patens exhibited higher ROS formation under salt stress (Frank et al., 2007). In a later study, the $\triangle P$ PTSPO1 mutant was shown to have increased levels of superoxide upon treatment with a fungal elicitor (Lehtonen et al., 2012). We, therefore, tested the impact of induced oxidative stress on WT and $\triangle F d T S P O$ cells. We analyzed ROS levels with the ROS-sensitive dichlorodihydrofluorescein diacetate (DCFH-DA) in GL- and RL-adapted $\triangle F d T S P O$ mutant and WT cells and in similarly grown cells after treatment with the electron acceptor MV or salt (Figure 6).

Green light- and RL-adapted cells showed only minor differences in ROS content between WT and mutant under standard conditions, with the mutant exhibiting significantly lower ROS levels under GL (Figure 6A). After $72 \mathrm{~h}$ of MV treatment, GL-grown $\triangle F d T S P O$ mutant cells exhibited a significantly higher ROS content than WT (Figure 6A). This result implies that the mutant is less equipped to cope with externally applied MV-induced stress. In the same manner, ROS content was measured in salt-stressed cells. The mutant exhibited significantly lower salt-induced ROS-levels after $72 \mathrm{~h}$ of treatment with $200 \mathrm{mM} \mathrm{NaCl}$ than WT under RL (Figure 6B). Notably, salt treatment did not result in an increase in ROS levels in WT under GL.

\section{FdTSPO is Transiently Up-regulated Under Stress}

The altered response of the $\triangle F d T S P O$ mutant to salt treatment and osmotic shock suggests a role for $F d T S P O$ in responses to stress in F. diplosiphon. To further understand the relationship between FdTSPO and salt stress, osmotic stress, and induced oxidative stress, we followed FdTSPO transcript accumulation over a period of 1 day, i.e., 3, 6, and $24 \mathrm{~h}$ after addition of $200 \mathrm{mM}$ salt, treatment with osmotic stress inducer sorbitol at 
$400 \mathrm{mM}$, or $0.3 \mu \mathrm{M}$ of oxidative stress inducer MV (Figure 7). After exhibiting a transient two-fold increase under RL and $\sim 1.5$-fold increase under GL at $3 \mathrm{~h}$, FdTSPO levels fell below the values observed before addition of salt (i.e., at $0 \mathrm{~h}$ ) after 6 and $24 \mathrm{~h}$ of stress (Figures 7A,B). The transient upregulation of FdTSPO implies a function in the early stages of salt stress response. FdTSPO was also transiently upregulated by $\sim$ fivefold at $6 \mathrm{~h}$ under RL with sorbitol treatment (Figure 7C). Expression was highest at $\sim 2.5$-fold after $24 \mathrm{~h}$ of sorbitol treatment in GL (Figure 7D). By comparison, after treatment with MV only a modest increase in expression was observed. After $6 \mathrm{~h}$ in GL, FdTSPO expression was significantly increased by $\sim 1.3$, with no significant upregulation of expression noted under RL (Figures 7E,F). Taken together, FdTSPO exhibited higher upregulation under stress conditions that were likely to occur under physiological conditions, i.e., salt and osmotic stresses.

\section{$\triangle F d T S P O$ Mutant Exhibits Changed Morphology under Different Light Conditions}

Given differential regulation of FdTSPO mRNA levels under GL vs. RL, we assessed additional phenotypes known to be GL- and RL-responsive in F. diplosiphon. WT cells are more round under $\mathrm{RL}$, whereas cells are more rectangular under GL (Bennett and Bogorad, 1973; Bordowitz and Montgomery, 2008). $\triangle F d T S P O$ cells are smaller under GL and RL (Figure 8A) and show a lower length:width ratio than the WT under GL, whereas the ratio is higher for the mutant than WT under RL (Figure 8B). Based on the observed difference in the length:width ratio, the $\triangle F d T S P O$ mutant seems to exhibit a morphology phenotype that is the inverse of that of the WT. $\triangle F d T S P O$ mutant cells indeed appear more round in GL and more rectangular under RL (Figure 8C). This effect could be due to FdTSPO directly impacting the regulation of cell morphology. Nevertheless, we cannot exclude the possibility that the altered cell morphology of the $\triangle F d T S P O$ mutant is due to some indirect effect caused by the lack of FdTSPO protein, which is a membrane protein.

\section{DISCUSSION}

Tryptophan-rich sensory protein is found in many organisms and despite many efforts the complete function of this protein is still not fully elucidated (Batoko et al., 2015; Campanella, 2015; Gut et al., 2015; Kim and Yu, 2015; Selvaraj and Stocco, 2015). We have analyzed TSPO from the chromatically acclimating cyanobacterium $F$. diplosiphon to better understand its function in photosynthetic organisms and to elucidate its function in cyanobacteria, for which there have been no published reports of functional studies. The level of sequence identity between some cyanobacterial TSPO homologs and the distinct genomic contexts observed in different organisms (Figure 1) may be explained by varying organismal habitats and different types of chromatic acclimation found in the cyanobacteria phylum (Carr and Whitton, 1982; Whitton and Potts, 2000). Functions unique to TSPO in a type III chromatically adapting cyanobacterium such as F. diplosiphon, which exhibits light-dependent changes in phycobiliprotein content (Bennett and Bogorad, 1973) and thus distinct light-dependent tetrapyrrole demands, are feasible.

The deletion of FdTSPO from the genome did not result in a great impact on cellular growth or pigment content under standard growth conditions (Figure 3, Supplementary Figures S2 and S3). By comparison, TSPO negatively affects photosynthetic pigment accumulation in Rhodobacter sphaeroides through negative regulation of transcription of carotenoid and bacteriochlorophyll biosynthesis genes, i.e., aerobically grown $\triangle R S T S P O$ mutant cells have higher levels of carotenoids and bacteriochlorophyll than WT; whereas TSPO overexpression results in reduced pigment content compared to the WT (Yeliseev and Kaplan, 1995). Also, overexpression of AtTSPO resulted in lower chlorophyll levels compared to the WT in Arabidopsis cells exposed to light (Guillaumot et al., 2009). Thus, FdTSPO might differ in its function from other photosynthetic organisms or a lack of FdTSPO may be compensated for by an unknown mechanism in $F$. diplosiphon resulting in only relatively small differences in the levels of photosynthetic pigmentation in the $\triangle F d T S P O$ mutant strain. Although $\triangle$ RsTSPO mutant cells were observed to accumulate higher pigment levels than WT in aerobic conditions, pigment levels converged to similar levels in the distinct strains after an acclimation period when cells were switched from aerobic to semi-aerobic growth (Yeliseev and Kaplan, 1995). Thus, the role for RsTSPO appears fine-tuned for regulating growth of this organism that exhibits anaerobic phototrophic growth and aerobic heterotrophic growth, very distinct from the aerobic phototroph F. diplosiphon. However, this role of RsTSPO in the transition from aerobic to anaerobic growth suggests a role for TSPO under changing environmental conditions, which may correlate with the observed effects of distinct wavelengths of light or composition of growth medium on FdTSPO expression levels.

Although salt has been previously shown to decrease chlorophyll and phycobiliprotein content in WT F. diplosiphon (Singh and Montgomery, 2013b), we observed specific saltdependent phenotypes in a $\triangle F d T S P O$ mutant relative to WT (Figure 4). Relatedly, a light-dependent salt susceptibility was reported for a TSPO mutant in $P$. patens when the mutant strain was switched from growth in the dark to a light/dark cycle (Frank et al., 2007). A lack of PpTSPO1 under high salt conditions resulted in shrinking of gametophores and protonema filaments, and ultimately in cell death (Frank et al., 2007). Previous studies with salt treatment also reported an upregulation of TSPO at both the transcriptional and protein level in plants (Frank et al., 2007; Guillaumot et al., 2009; Balsemão-Pires et al., 2011) and at the transcriptional level in Pseudomonas (Leneveu-Jenvrin et al., 2015). In A. thaliana, an AtTSPO overexpression line exhibited a growth deficiency under salt stress compared to WT and a mutant line (Guillaumot et al., 2009). By comparison, salt-dependent bleaching was observed in PpTSPO mutant lines, but not WT (Frank et al., 2007). An elevated upregulation of stress marker genes, including drought responsive genes, was observed in the AtTSPO knock out line compared to the WT in response to salt (Balsemão-Pires et al., 2011). Thus, although correlated with saltdependent responses in several photosynthetic organisms, the 
specific role for TSPO in response to stress can differ in distinct organisms.

Salt-stressed cyanobacterial cells have been reported to exhibit higher levels of ROS (Srivastava et al., 2005), reduced chlorophyll and phycobiliprotein content (Srivastava et al., 2008; Singh and Montgomery, 2013b), decreased oxygen evolution, decreased carbon fixation, and increased respiration (Srivastava et al., 2008). The lowered ROS content of the $\triangle F d T S P O$ mutant in response to salt could be a consequence of lowered pigment content in the mutant leading to decreased light absorption, possibly causing less ROS to be formed and thereby improving fitness under salt stress. On the other hand increased levels of superoxide dismutase and catalase upon salt stress have been reported in cyanobacteria (Srivastava et al., 2008; Srivastava, 2010). In plants, catalase is inhibited under salt stress (Foyer et al., 1994), whereas overexpression of E. coli catalase in Synechococcus infers resistance to salt stress (Kaku et al., 2000). It is therefore possible that FdTSPO influences ROS levels under salt stress through impacting cellular ROS detoxification capacity, which correlates with ROS-detoxification mechanisms (Busch and Montgomery, 2015).

The potential function of TSPO in the salt stress response in plants has become clearer with the recent finding of a physical interaction of AtTSPO with an aquaporin (Hachez et al., 2014). These findings suggest a role of AtTSPO in negative posttranscriptional regulation of aquaporin in the early stress response that is associated with a prevention of water loss upon salt stress (Hachez et al., 2014). Transient upregulation of TSPO early during exponential phase growth of Pseudomonas in response to salt treatment also has been noted (Leneveu-Jenvrin et al., 2015). These results are consistent with our observations that place TSPO in the early stress response and fine-tuning of the regulation of this response in F. diplosiphon.

Our observations suggest an involvement of FdTSPO in abiotic stress responses. In the absence of FdTSPO, parts of the early stress response involving energy-requiring, FdTSPOdependent acclimation processes are likely impaired resulting in a transient advantage for the mutant cell under salt stress. By contrast, the absence of FdTSPO under osmotic stress impairs the ability of cells to grow and survive under GL. In the presence of extreme oxidative stress, as in the case of externally applied MV, a lack of FdTSPO accompanied by a misregulated stress response would result in higher ROS generation and elevated cell death. The greater effect of MVinduced ROS generation under GL compared to RL is likely due to an already upregulated oxidative stress response machinery under RL compared to GL (Pattanaik et al., 2014). Dysregulation of tetrapyrrole metabolism as well as iron limitation might

\section{REFERENCES}

Aravind Menon, I., Persad, S. D., and Haberman, H. B. (1989). A comparison of the phototoxicity of protoporphyrin, coproporphyrin and uroporphyrin using a cellular system in vitro. Clin. Biochem. 22, 197-200. doi: 10.1016/S0009-9120(89) 80077-3 contribute to this increase in ROS (Kruse et al., 1995; Michel and Pistorius, 2004; Latifi et al., 2005; Jung et al., 2008; Pattanaik et al., 2014). We recently demonstrated that sensory light-perception and iron availability are intertwined with ROS formation and the oxidative stress response in F. diplosiphon (Pattanaik et al., 2014), processes in which FdTSPO might be involved or through which it is regulated (Table 1).

The $\triangle F d T S P O$ mutant exhibited altered light-dependent regulation of cellular morphology compared to WT (Figure 8). The morphology phenotype observed for the $\triangle F d T S P O$ mutant could be due to perturbations in the light-quality mediated regulation of morphology (Bordowitz and Montgomery, 2008), especially given light quality-dependent regulation of FdTSPO mRNA accumulation. On the other hand, as TSPO is a predicted membrane protein, we cannot exclude the possibility that a lack of FdTSPO causes an indirect morphological change.

We found TSPO from $F$. diplosiphon to be involved in stress-related processes, specifically salt, osmotic and oxidative stresses. TSPO has been implicated in stress responses in photosynthetic organisms before (Frank et al., 2007; BalsemãoPires et al., 2011). We found a unique connection to lightquality-related processes specific to a chromatically acclimating cyanobacterium, including higher resistance to salt stress under $\mathrm{RL}$ compared to GL, and higher susceptibility to osmotic stress and MV-induced oxidative stress under GL compared to $\mathrm{RL}$ in the mutant. Thus, TSPO seems to share certain functionalities across kingdoms, while having evolved speciesspecific functions.

\section{AUTHOR CONTRIBUTIONS}

$\mathrm{AB}$ and $\mathrm{BM}$ conceived and designed experiments, and $\mathrm{AB}$ conducted experiments. $\mathrm{AB}$ and $\mathrm{BM}$ analyzed data and wrote and edited the paper.

\section{FUNDING}

This work was supported by the National Science Foundation (grant no. MCB-1243983 to BM).

\section{SUPPLEMENTARY MATERIAL}

The Supplementary Material for this article can be found online at: http://journal.frontiersin.org/article/10.3389/fmicb. 2015.01393

Armstrong, G. A. (1998). Greening in the dark: light-independent chlorophyll biosynthesis from anoxygenic photosynthetic bacteria to gymnosperms. J. Photochem. Photobiol. B Biol. 43, 87-100. doi: 10.1016/S1011-1344(98) 00063-3

Baier, A., Winkler, W., Korte, T., Lockau, W., and Karradt, A. (2014). Degradation of phycobilisomes in Synechocystis sp. PCC6803: evidence for essential formation of an NblA1/NblA2 heterodimer and its codegradation 
by a Clp protease complex. J. Biol. Chem. 289, 11755-11766. doi: 10.1074/jbc.M113.520601

Baier, K., Lehmann, H., Stephan, D. P., and Lockau, W. (2004). NblA is essential for phycobilisome degradation in Anabaena sp. strain PCC 7120 but not for development of functional heterocysts. Microbiology 150, 2739-2749. doi: 10.1099/mic.0.27153-0

Balsemão-Pires, E., Jaillais, Y., Olson, B. J. S. C., Andrade, L. R., Umen, J. G., Chory, J., et al. (2011). The Arabidopsis translocator protein (AtTSPO) is regulated at multiple levels in response to salt stress and perturbations in tetrapyrrole metabolism. BMC Plant Biol. 11:108. doi: 10.1186/1471-22 29-11-108

Batoko, H., Veljanovski, V., and Jurkiewicz, P. (2015). Enigmatic Translocator protein (TSPO) and cellular stress regulation. Trends Biochem. Sci. 40, 497-503. doi: 10.1016/j.tibs.2015.07.001

Bennett, A., and Bogorad, L. (1973). Complementary chromatic adaptation in a filamentous blue-green alga. J. Cell Biol. 58, 419-435. doi: 10.1083/jcb.58.2.419

Biswas, A., Boutaghou, M. N., Alvey, R. M., Kronfel, C. M., Cole, R. B., Bryant, D. A., et al. (2011). Characterization of the activities of the CpeY, CpeZ, and CpeS bilin lyases in phycoerythrin biosynthesis in Fremyella diplosiphon strain UTEX 481. J. Biol. Chem. 286, 35509-35521. doi: 10.1074/jbc.M111.284281

Bordowitz, J. R., and Montgomery, B. L. (2008). Photoregulation of cellular morphology during complementary chromatic adaptation requires sensorkinase-class protein RcaE in Fremyella diplosiphon. J. Bacteriol. 190, 4069-4074. doi: 10.1128/JB.00018-08

Bordowitz, J. R., and Montgomery, B. L. (2010). Exploiting the autofluorescent properties of photosynthetic pigments for analysis of pigmentation and morphology in live Fremyella diplosiphon cells. Sensors 10, 6969-6979. doi: $10.3390 / \mathrm{s} 100706969$

Braestrup, C., Albrechtsen, R., and Squires, R. F. (1977). High-densities of benzodiazepine receptors in human cortical areas. Nature 269, 702-704. doi: $10.1038 / 269702 \mathrm{a} 0$

Busch, A. W. U., and Montgomery, B. L. (2015). Interdependence of tetrapyrrole metabolism, the generation of oxidative stress and the mitigative oxidative stress response. Redox Biol. 4, 260-271. doi: 10.1016/j.redox.2015.01.010

Campanella, M. (2015). TSPO the unrested: challenged opinions of a resourceful mitochondrial protein. Trends Endocrinol. Metab. 26, 333-334. doi: 10.1016/j.tem.2015.05.003

Carr, N. G., and Whitton, B. A. (1982). The Biology of Cyanobacteria. Oxford: Blackwell Scientific.

Chitnis, V. P., and Chitnis, P. R. (1993). Psal subunit is required for the formation of photosystem-I trimers in the cyanobacterium Synechocystis sp. PCC 6803. FEBS Lett. 336, 330-334. doi: 10.1016/0014-5793(93)80831-E

Cobley, J., Seneviratne, L., Drong, L., Thounaojam, M., Oda, J. F., and Carroll, J. (1999). "Transposition of Tn5 derivatives in the chromatically adapting cyanobacterium, Fremyella diplosiphon," in The Phototrophic Prokaryotes, eds G. Peschek, W. Löffelhardt, and G. Schmetterer (New York, NY: Kluwer Academic), 443-451. doi: 10.1007/978-1-4615-4827-0_52

Cobley, J. G., Clark, A. C., Weerasurya, S., Queseda, F. A., Xiao, J. Y., Bandrapali, N., et al. (2002). CpeR is an activator required for expression of the phycoerythrin operon (cpeBA) in the cyanobacterium Fremyella diplosiphon and is encoded in the phycoerythrin linker-polypeptide operon (cpeCDESTR). Mol. Microbiol. 44, 1517-1531. doi: 10.1046/j.1365-2958.2002.02966.x

Cobley, J. G., Zerweck, E., Reyes, R., Mody, A., Seludo-Unson, J. R., Jaeger, H., et al. (1993). Construction of shuttle plasmids which can be efficiently mobilized from Escherichia coli into the chromatically adapting cyanobacterium, Fremyella diplosiphon. Plasmid 30, 90-105. doi: 10.1006/plas.1993.1037

Colasanti, A., Owen, D. R., Grozeva, D., Rabiner, E. A., Matthews, P. M., Craddock, N., et al. (2013). Bipolar disorder is associated with the rs6971 polymorphism in the gene encoding $18 \mathrm{kDa}$ Translocator Protein (TSPO). Psychoneuroendocrinology 38, 2826-2829. doi: 10.1016/J.Psyneuen.2013.07.007

Collier, J. L., and Grossman, A. R. (1994). A small polypeptide triggers complete degradation of light-harvesting phycobiliproteins in nutrientdeprived cyanobacteria. EMBO J. 13, 1039-1047.

Conley, P. B., Lemaux, P. G., and Grossman, A. R. (1988). Molecular characterization and evolution of sequences encoding light-harvesting components in the chromatically adapting cyanobacterium Fremyella diplosiphon. J. Mol. Biol. 199, 447-465. doi: 10.1016/0022-2836(88) 90617-1
Davey, M. E., and de Bruijn, F. J. (2000). A homologue of the tryptophan-rich sensory protein TspO and FixL regulate a novel nutrient deprivation-induced Sinorhizobium meliloti locus. Appl. Environ. Microbiol. 66, 5353-5359. doi: 10.1128/aem.66.12.5353-5359.2000

Dere, S., Güneş, T., and Sivaci, R. (1998). Spectrophotometric determination of chlorophyll - a, b and total carotenoid contents of some algae species using different solvents. Turk. J. Bot. 22, 8-13.

Edgar, R. C. (2004). MUSCLE: multiple sequence alignment with high accuracy and high throughput. Nucleic Acids Res. 32, 1792-1797. doi: 10.1093/nar/ gkh340

Elhai, J., and Wolk, C. P. (1988). Conjugal transfer of DNA to cyanobacteria. Methods Enzymol. 167, 747-754. doi: 10.1016/0076-6879(88)67 086-8

Ferreira, G. C., Franco, R., Lloyd, S. G., Moura, I., Moura, J. J., and Huynh, B. H. (1995). Structure and function of ferrochelatase. J. Bioenerg. Biomembr. 27, 221-229. doi: 10.1007/BF02110037

Foyer, C. H., Lelandais, M., and Kunert, K. J. (1994). Photooxidative stress in plants. Physiol. Plant. 92, 696-717. doi: 10.1111/J.1399-3054.1994.Tb03042.X

Frank, W., Baar, K. M., Qudeimat, E., Woriedh, M., Alawady, A., Ratnadewi, D., et al. (2007). A mitochondrial protein homologous to the mammalian peripheral-type benzodiazepine receptor is essential for stress adaptation in plants. Plant J. 51, 1004-1018. doi: 10.1111/J.1365-313x.2007.03 198.X

Frankenberg, N., Mukougawa, K., Kohchi, T., and Lagarias, J. C. (2001). Functional genomic analysis of the HY2 family of ferredoxin-dependent bilin reductases from oxygenic photosynthetic organisms. Plant Cell 13, 965-978. doi: $10.2307 / 3871353$

Grossman, A. R., Schaefer, M. R., Chiang, G. G., and Collier, J. L. (1993). The phycobilisome, a light-harvesting complex responsive to environmental conditions. Microbiol. Rev. 57, 725-749.

Guillaumot, D., Guillon, S., Deplanque, T., Vanhee, C., Gumy, C., Masquelier, D., et al. (2009). The Arabidopsis TSPO-related protein is a stress and abscisic acidregulated, endoplasmic reticulum-Golgi-localized membrane protein. Plant $\mathrm{J}$. 60, 242-256. doi: 10.1111/j.1365-313X.2009.03950.x

Gut, P., Zweckstetter, M., and Banati, R. B. (2015). Lost in translocation: the functions of the $18-\mathrm{kD}$ translocator protein. Trends Endocrinol. Metab. 26, 349-356. doi: 10.1016/j.tem.2015.04.001

Gutu, A., and Kehoe, D. M. (2012). Emerging perspectives on the mechanisms, regulation, and distribution of light color acclimation in cyanobacteria. Mol. Plant 5, 1-13. doi: $10.1093 / \mathrm{mp} / \mathrm{ssr} 054$

Hachez, C., Veljanovski, V., Reinhardt, H., Guillaumot, D., Vanhee, C., Chaumont, F., et al. (2014). The Arabidopsis abiotic stress-induced TSPOrelated protein reduces cell-surface expression of the aquaporin PIP2;7 through protein-protein interactions and autophagic degradation. Plant Cell 26, 49744990. doi: $10.1105 /$ tpc. 114.134080

Hagemann, M. (2011). Molecular biology of cyanobacterial salt acclimation. FEMS Microbiol. Rev. 35, 87-123. doi: 10.1111/j.1574-6976.2010.00 234.x

Hörtensteiner, S., Vicentini, F., and Matile, P. (1995). Chlorophyll breakdown in senescent cotyledons of rape, Brassica napus L. - enzymatic cleavage of phaeophorbide a in vitro. New Phytol. 129, 237-246. doi: 10.1111/J.14698137.1995.Tb04293.X

Jung, S., Lee, H. J., Lee, Y., Kang, K., Kim, Y. S., Grimm, B., et al. (2008). Toxic tetrapyrrole accumulation in protoporphyrinogen IX oxidase-overexpressing transgenic rice plants. Plant Mol. Biol. 67, 535-546. doi: 10.1007/s11103-0089338-0

Kahn, K., Mazel, D., Houmard, J., Demarsac, N. T., and Schaefer, M. R. (1997). A role for cpeYZ in cyanobacterial phycoerythrin biosynthesis. J. Bacteriol. 179, 998-1006.

Kaku, N., Hibino, T., Tanaka, Y., Ishikawa, H., Araki, E., Takabe, T., et al. (2000). Effects of overexpression of Escherichia coli katE and bet genes on the tolerance for salt stress in a freshwater cyanobacterium Synechococcus sp PCC 7942. Plant Sci. 159, 281-288. doi: 10.1016/S0168-9452(00) 00353-8

Karradt, A., Sobanski, J., Mattow, J., Lockau, W., and Baier, K. (2008). NblA, a key protein of phycobilisome degradation, interacts with ClpC, a HSP100 chaperone partner of a cyanobacterial Clp protease. J. Biol. Chem. 283, 3239432403. doi: $10.1074 / J b c . M 805823200$ 
Kehoe, D. M., and Grossman, A. R. (1994). Complementary chromatic adaptation: photoperception to gene regulation. Semin. Cell Biol. 5, 303-313. doi: 10.1006/scel.1994.1037

Kehoe, D. M., and Grossman, A. R. (1996). Similarity of a chromatic adaptation sensor to phytochrome and ethylene receptors. Science 273, 1409-1412. doi: $10.1126 /$ science.273.5280.1409

Kehoe, D. M., and Gutu, A. (2006). Responding to color: the regulation of complementary chromatic adaptation. Annu. Rev. Plant Biol. 57, 127-150. doi: 10.1146/annurev.arplant.57.032905.105215

Kim, E.-J., and Yu, S.-W. (2015). Translocator protein $18 \mathrm{kDa}$ (TSPO): old dogma, new mice, new structure, and new questions for neuroprotection. Neural Regen. Res. 10, 878-880. doi: 10.4103/1673-5374.15 8338

Kruse, E., Mock, H. P., and Grimm, B. (1995). Reduction of coproporphyrinogen oxidase level by antisense RNA synthesis leads to deregulated gene expression of plastid proteins and affects the oxidative defense system. EMBO J. 14, 3712-3720.

Latifi, A., Jeanjean, R., Lemeille, S., Havaux, M., and Zhang, C. C. (2005). Iron starvation leads to oxidative stress in Anabaena sp. strain PCC 7120. J. Bacteriol. 187, 6596-6598. doi: 10.1128/JB.187.18.6596-65 98.2005

Lehtonen, M. T., Akita, M., Frank, W., Reski, R., and Valkonen, J. P. T. (2012). Involvement of a class III peroxidase and the mitochondrial protein TSPO in oxidative burst opon treatment of moss plants with a fungal elicitor. Mol. Plant Microbe Interact. 25, 363-371. doi: 10.1094/Mpmi-10-11-0265

Leneveu-Jenvrin, C., Bouffartigues, E., Maillot, O., Cornelis, P., Feuilloley, M. G. J., Connil, N., et al. (2015). Expression of the translocator protein (TSPO) from Pseudomonas fluorescens $\mathrm{Pfo}-1$ requires the stress regulatory sigma factors $\mathrm{AlgU}$ and RpoH. Front. Microbiol. 6:1023. doi: 10.3389/fmicb.2015.01023

Leneveu-Jenvrin, C., Connil, N., Bouffartigues, E., Papadopoulos, V., Feuilloley, M. G. J., and Chevalier, S. (2014). Structure-to-function relationships of bacterial translocator protein (TSPO): a focus on Pseudomonas. Front. Microbiol. 5:631. doi: 10.3389/fmicb.2014.00631

Luque, I., Ochoa De Alda, J. A., Richaud, C., Zabulon, G., Thomas, J. C., and Houmard, J. (2003). The NblAI protein from the filamentous cyanobacterium Tolypothrix PCC 7601: regulation of its expression and interactions with phycobilisome components. Mol. Microbiol. 50, 1043-1054. doi: 10.1046/j.1365-2958.2003.03 768.x

Martinez-Guerrero, C. E., Ciria, R., Abreu-Goodger, C., Moreno-Hagelsieb, G., and Merino, E. (2008). GeConT 2: gene context analysis for orthologous proteins, conserved domains and metabolic pathways. Nucleic Acids Res. 36, W176-W180. doi: 10.1093/nar/gkn330

Mazel, D., Guglielmi, G., Houmard, J., Sidler, W., Bryant, D. A., and Tandeau De Marsac, N. (1986). Green light induces transcription of the phycoerythrin operon in the cyanobacterium Calothrix 7601. Nucleic Acids Res. 14, 8279-8290. doi: 10.1093/nar/14.21.8279

Michel, K. P., and Pistorius, E. K. (2004). Adaptation of the photosynthetic electron transport chain in cyanobacteria to iron deficiency: the function of IdiA and IsiA. Physiol. Plant. 120, 36-50. doi: 10.1111/j.0031-9317.2004.0229.x

Montgomery, B., Karrakat, B., and Oh, S. (2015). Molecular basis and fitness implications of the interplay between light and the regulation of iron homeostasis in photosynthetic organisms. Environ. Exp. Bot. 114, 48-56. doi: 10.1016/j.envexpbot.2014.06.018

Narayan, O. P., Kumari, N., and Rai, L. C. (2011). Iron starvation-induced proteomic changes in Anabaena (Nostoc) sp. PCC 7120: exploring survival strategy. J. Microbiol. Biotechnol. 21, 136-146. doi: 10.4014/jmb.1009.09021

Papadopoulos, V., Baraldi, M., Guilarte, T. R., Knudsen, T. B., Lacapere, J. J., Lindemann, P., et al. (2006). Translocator protein (18 kDa): new nomenclature for the peripheral-type benzodiazepine receptor based on its structure and molecular function. Trends Pharmacol. Sci. 27, 402-409. doi: 10.1016/J.Tips.2006.06.005

Pattanaik, B., Busch, A. W., Hu, P., Chen, J., and Montgomery, B. L. (2014). Responses to iron limitation are impacted by light quality and regulated by $\mathrm{RcaE}$ in the chromatically acclimating cyanobacterium Fremyella diplosiphon. Microbiology 160, 992-1005. doi: 10.1099/mic.0.075 192-0
Pattanaik, B., and Montgomery, B. L. (2010). FdTonB is involved in the photoregulation of cellular morphology during complementary chromatic adaptation in Fremyella diplosiphon. Microbiology 156, 731-741. doi: 10.1099/mic.0.035410-0

Seib, L. O., and Kehoe, D. M. (2002). A turquoise mutant genetically separates expression of genes encoding phycoerythrin and its associated linker peptides. J. Bacteriol. 184, 962-970. doi: 10.1128/jb.184.4.962-970.2002

Selvaraj, V., and Stocco, D. M. (2015). The changing landscape in translocator protein (TSPO) function. Trends Endocrinol. Metab. 26, 341-348. doi: 10.1016/j.tem.2015.02.007

Singh, S. P., and Montgomery, B. L. (2012). Reactive oxygen species are involved in the morphology-determining mechanism of Fremyella diplosiphon cells during complementary chromatic adaptation. Microbiology 158, 2235-2245. doi: 10.1099/Mic.0.060475-0

Singh, S. P., and Montgomery, B. L. (2013a). Distinct salt-dependent effects impair Fremyella diplosiphon pigmentation and cellular shape. Plant Signal. Behav. 8, e24713. doi: 10.4161/psb.24713

Singh, S. P., and Montgomery, B. L. (2013b). Salinity impacts photosynthetic pigmentation and cellular morphology changes by distinct mechanisms in Fremyella diplosiphon. Biochem. Biophys. Res. Commun. 433, 84-89. doi: 10.1016/j.bbrc. 2013.02 .060

Srivastava, A., Bhargava, P., Thapar, R., and Rai, L. (2008). Salinity-induced physiological and proteomic changes in Anabaena doliolum. Environ. Exp. Bot. 64, 49-57. doi: 10.1016/j.envexpbot.2007.12.012

Srivastava, A. K. (2010). Assessment of salinity-induced antioxidative defense system of diazotrophic cyanobacterium Nostoc muscorum. J. Microbiol. Biotechnol. 20, 1506-1512. doi: 10.4014/Jmb.100 5.05037

Srivastava, A. K., Bhargava, P., and Rai, L. C. (2005). Salinity and copper-induced oxidative damage and changes in the antioxidative defence systems of Anabaena doliolum. World J. Microbiol. Biotechnol. 21, 1291-1298. doi: 10.1007/S11274005-2442-2

Stowe-Evans, E. L., Ford, J., and Kehoe, D. M. (2004). Genomic DNA microarray analysis: identification of new genes regulated by light color in the cyanobacterium Fremyella diplosiphon. J. Bacteriol. 186, 4338-4349. doi: 10.1128/JB.186.13.4338-4349.2004

Takemoto, J., and Bogorad, L. (1975). Subunits of phycoerythrin from Fremyella diplosiphon: chemical and immunochemical characterization. Biochemistry 14, 1211-1216. doi: 10.1021/bi00677a018

Tandeau de Marsac, N., and Houmard, J. (1988). Complementary chromatic adaptation - physiological conditions and action spectra. Methods Enzymol. 167, 318-328. doi: 10.1016/0076-6879(88) 67037-6

Tandeau de Marsac, N., Mazel, D., Damerval, T., Guglielmi, G., Capuano, V., and Houmard, J. (1988). Photoregulation of gene expression in the filamentous cyanobacterium Calothrix sp. PCC 7601: light-harvesting complexes and cell differentiation. Photosyn. Res. 18, 99-132. doi: 10.1007/BF0004 2981

Terauchi, K., Montgomery, B. L., Grossman, A. R., Lagarias, J. C., and Kehoe, D. M. (2004). RcaE is a complementary chromatic adaptation photoreceptor required for green and red light responsiveness. Mol. Microbiol. 51, 567-577. doi: 10.1046/j.1365-2958.2003.03853.x

Tu, L. N., Morohaku, K., Manna, P. R., Pelton, S. H., Butler, W. R., Stocco, D. M., et al. (2014). Peripheral benzodiazepine receptor/translocator protein global knockout mice are viable with no effects on steroid hormone biosynthesis. J. Biol. Chem. 289, 444-454. doi: 10.1074/jbc.M114.5 78286

Unno, M., Matsui, T., and Ikeda-Saito, M. (2007). Structure and catalytic mechanism of heme oxygenase. Nat. Prod. Rep. 24, 553-570. doi: 10.1039/b604180a

Vanhee, C., Zapotoczny, G., Masquelier, D., Ghislain, M., and Batoko, H. (2011). The Arabidopsis multistress regulator TSPO is a heme binding membrane protein and a potential scavenger of porphyrins via an autophagy-dependent degradation mechanism. Plant Cell 23, 785-805. doi: 10.1105/tpc.110.0 81570

Warren, M. J., and Smith, A. G. (eds) (2009). Tetrapyrroles: Birth, Life and Death. New York, NY: Springer-Verlag New York. 
Watanabe, M., and Ikeuchi, M. (2013). Phycobilisome: architecture of a lightharvesting supercomplex. Photosyn. Res. 116, 265-276. doi: 10.1007/s11120013-9905-3

Wendler, G., Lindemann, P., Lacapere, J. J., and Papadopoulos, V. (2003). Protoporphyrin IX binding and transport by recombinant mouse PBR. Biochem. Biophys. Res. Commun. 311, 847-852. doi: 10.1016/J.Bbrc.2003. 10.070

Whitton, B. A., and Potts, M. (2000). The Ecology of Cyanobacteria : Their Diversity in Time and Space. London: Kluwer Academic.

$\mathrm{Wu}, \mathrm{X} . \mathrm{T}$., and Gallo, K. A. (2013). The $18-\mathrm{kDa}$ translocator protein (TSPO) disrupts mammary epithelial morphogenesis and promotes breast cancer cell migration. PLoS ONE 8:e71258. doi: 10.1371/journal.pone.0071258

Yeliseev, A. A., and Kaplan, S. (1995). A sensory transducer homologous to the mammalian peripheral-type benzodiazepine receptor regulates photosynthetic membrane complex formation in Rhodobacter sphaeroides 2.4.1. J. Biol. Chem. 270, 21167-21175. doi: 10.1074/jbc.270.36.21167
Yeliseev, A. A., and Kaplan, S. (1999). A novel mechanism for the regulation of photosynthesis gene expression by the TspO outer membrane protein of Rhodobacter sphaeroides 2.4.1. J. Biol. Chem. 274, 21234-21243. doi: 10.1074/Jbc.274.30.212347

Conflict of Interest Statement: The authors declare that the research was conducted in the absence of any commercial or financial relationships that could be construed as a potential conflict of interest.

Copyright $\odot 2015$ Busch and Montgomery. This is an open-access article distributed under the terms of the Creative Commons Attribution License (CC BY). The use, distribution or reproduction in other forums is permitted, provided the original author(s) or licensor are credited and that the original publication in this journal is cited, in accordance with accepted academic practice. No use, distribution or reproduction is permitted which does not comply with these terms. 